\title{
1 The contribution of insects to global forest deadwood
}

2 decomposition

4 Sebastian Seibold*, Werner Rammer, Torsten Hothorn, Rupert Seidl, Michael D. Ulyshen,

5 Janina Lorz, Marc W. Cadotte, David B. Lindenmayer, Yagya P. Adhikari, Roxana Aragón, 6 Soyeon Bae, Petr Baldrian, Hassan Barimani Varandi, Jos Barlow, Claus Bässler, Jacques 7 Beauchêne, Erika Berenguer, Rodrigo S. Bergamin, Tone Birkemoe, Gergely Boros, Roland 8 Brandl, Hervé Brustel, Philip J. Burton, Yvonne T. Cakpo-Tossou, Jorge Castro, Eugénie 9 Cateau, Tyler P. Cobb, Nina Farwig, Romina D. Fernández, Jennifer Firn, Kee Seng Gan, 10 Grizelle González, Martin M. Gossner, Jan C. Habel, Christian Hébert, Christoph Heibl, Osmo 11 Heikkala, Andreas Hemp, Claudia Hemp, Joakim Hjältén, Stefan Hotes, Jari Kouki, Thibault 12 Lachat, Jie Liu, Yu Liu, Ya-Huang Luo, Damasa M. Macandog, Pablo E. Martina, Sharif A. 13 Mukul, Baatarbileg Nachin, Kurtis Nisbet, John O'Halloran, Anne Oxbrough, Jeev Nath 14 Pandey, Tomáš Pavlíček, Stephen M. Pawson, Jacques S. Rakotondranary, Jean-Baptiste 15 Ramanamanjato, Liana Rossi, Jürgen Schmidl, Mark Schulze, Stephen Seaton, Marisa J. 16 Stone, Nigel E. Stork, Byambagerel Suran, Anne Sverdrup-Thygeson, Simon Thorn, Ganesh

17 Thyagarajan, Timothy J. Wardlaw, Wolfgang W. Weisser, Sungsoo Yoon, Naili Zhang, Jörg 18 Müller *corresponding author: sebastian.seibold@tum.de

20 Affiliations: see attachment 


\section{Summary}

22 The amount of carbon stored in deadwood is equivalent to about $8 \%$ of global forest

23 carbon stocks ${ }^{1}$. Deadwood decomposition is largely governed by climate ${ }^{2-5}$ with 24 decomposer groups, such as microbes and insects, contributing to variations in decomposition rates ${ }^{2,6,7}$. At the global scale, the contribution of insects to deadwood decomposition and carbon release remains poorly understood ${ }^{7}$. Here we present a field experiment of wood decomposition across 55 forest sites on six continents. We find that deadwood decomposition rates increase with temperature, with the strongest temperature effect at high precipitation levels. Precipitation affects decomposition rates negatively at low temperature and positively at high temperatures. As net effect, including direct consumption and indirect effects via interactions with microbes, insects accelerate decomposition in tropical forests (3.9\% median mass loss per year). In temperate and boreal forests we find weak positive and negative effects with a median mass loss of $0.9 \%$ and $-0.1 \%$ per year, respectively. Furthermore, we apply the experimentally derived decomposition function to a global map of deadwood carbon synthesised from empirical and remote sensing data. This allows for a first estimate of $10.9 \pm 3.2 \mathrm{Pg} \mathrm{yr}^{-1}$ of carbon released from deadwood globally, with $93 \%$ originating from tropical forests. Globally, the net effect of insects accounts for a carbon flux of $3.2 \pm 0.9$

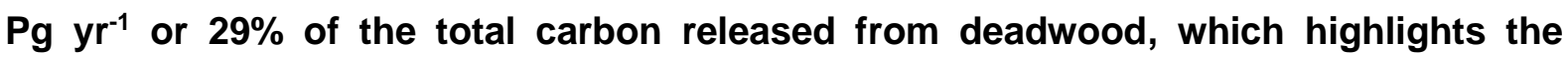
functional importance of insects for deadwood decomposition and the global carbon cycle. 
The world's forests are an important carbon sink ${ }^{1}$, but global climate change is affecting carbon sequestration and release by altering tree growth ${ }^{8,9}$, mortality ${ }^{10,11}$ and decomposition ${ }^{12,13}$. Hence, a comprehensive understanding of the forest carbon cycle and its climate sensitivity is critical for improving global climate change projections. While past research has focused strongly on sequestration ${ }^{14,15}$, carbon release, including the decomposition of deadwood, remain poorly understood ${ }^{7,16}$. Deadwood currently stores $73 \pm 6 \mathrm{Pg}$ (Petagram, $10^{15} \mathrm{~g}$ ) of carbon globally, which is about $8 \%$ of the global forest carbon stock ${ }^{1}$ and $8.5 \%$ of atmospheric carbon $^{17}$. Deadwood decomposition is largely governed by climate ${ }^{2-5}$, with the activity of different decomposer groups contributing to the considerable variation in decomposition rates $^{2,6,7}$. Recently, the role of fungi in forest carbon cycling has received much attention ${ }^{2,6}$ and they are believed to be the principal decomposers of deadwood ${ }^{5-7}$. While local and regionalscale studies indicate that insects can also make a considerable contribution to wood decomposition ${ }^{7}$, global assessments quantifying the role of microbes and insects are lacking. Given the sensitivity of insects to climate change ${ }^{19,20}$ and the observed declines in insect biodiversity $^{21-23}$, a better understanding of the interactions between insect decomposers and climate is needed to more robustly project carbon flux from deadwood and the role of deadwood in the global forest carbon sink $\mathrm{k}^{11,16,24}$.

Here, we quantified the role of deadwood-decomposing insects relative to climate by conducting standardised field experiments of wood decomposition across 55 sites on six continents (Fig. 1a). Our sites were selected to capture the gradient of temperature and precipitation conditions under which forests occur globally. Insects and other animals (hereafter collectively termed insects for brevity) had unrestricted access to wood placed on the forest floor in the uncaged treatment in our experiment, while they were excluded from wood in the closed cage treatment using mesh cages (Extended Data Fig. 1). Our estimate of the effect of insects on wood decomposition was quantified as the difference between decomposition rates in the uncaged and closed cage treatments. This measure can be 
considered the "net effect of insects", consisting of direct consumption of wood by insects and indirect effects via interactions with microbes. The latter include, for example, competition for resources, grazing on fungal mycelia, creation of entry ports or vectoring, and can thus either increase $^{25}$ or decrease wood decomposition ${ }^{26,27}$. Consequently, direct consumption by insects could be higher than our net estimate where insect-microbe interactions decrease decomposition rates. To explore effects of caging on microclimatic conditions and decomposition rates, we implemented a third treatment (open cage) using cages with holes, allowing insects access to wood samples under similar microclimatic conditions to those in the closed cage treatment (Supplementary Information section 1). We assessed wood decomposition as mass loss over a period of up to three years for wood samples with bark ( $\sim 3 \mathrm{~cm}$ in diameter, $50 \mathrm{~cm}$ in length) of locally dominant native tree species (142 tree species in total) as well as for standardized wooden dowels without bark. In total, we recorded wood mass loss for 4437 individual samples. We used a Gaussian generalized linear mixed log-link model with site-specific random effects to quantify the influence of insects (uncaged vs. closed cage), site-level temperature and precipitation as well as type of wood (angiosperm vs. gymnosperm) on the annual rates of wood mass loss. Although some influence of caging on microclimate cannot be ruled out, we focused on the comparison between uncaged and closed cage treatments, because analyses across treatments indicated that this comparison provides the most robust estimate for the net effect of insects on wood decomposition (Supplementary Information section 1; Extended Data Table 1; Extended Data Fig. 2).

To provide a first estimate of the global carbon flux from deadwood decomposition (henceforth referred to as deadwood carbon release) and to quantify the functional importance of insects for global deadwood carbon, we applied the model derived from our decomposition experiment to a novel global deadwood carbon map (Fig. 1a), which we synthesized from empirical and remote-sensing data. As the global modelling of deadwood remains challenging, we conducted in-depth analyses of uncertainty, evaluating the decomposition function derived from our experiment against independent empirical data ${ }^{28}$ and quantifying the relative 
contribution of different sources of uncertainty in a sensitivity analysis (Supplementary

97 Information section 2 and Extended Data Table 2). The sensitivity analysis also highlights how further research can improve the modelling of global carbon fluxes from deadwood.

\section{Climate and insect effects}

In our global experiment, wood decomposition rate was highest in the tropics/subtropics (henceforth called tropics; median $=28.2 \%$ mass loss per year), and was considerably lower in the temperate $($ median $=6.3 \%$ ) and boreal $/$ hemiboreal (henceforth called boreal; median $=$ 3.3\%; Fig. 1b) biomes. Wood decomposition rates were highly climate-sensitive, driven by the complex interplay between temperature and precipitation (Table 1). Decomposition rates increased with increasing temperature across the full gradient of precipitation, but the effects of temperature were strongest at high levels of precipitation (Fig. 2a; Extended Data Fig. 3a). Precipitation affected decomposition rates negatively at low temperatures but positively at high temperatures. The observed positive global relationship between wood decomposition and temperature was similar to patterns observed at local to continental scales ${ }^{2,4}$, as well as for the decomposition of non-woody litter ${ }^{12,29}$, and is consistent with general theory predicting an increase in metabolic rates and enzymatic activity with temperature ${ }^{30}$. Moreover, the length of the vegetation period usually increases with temperature which may further increase annual decomposition rates. Weaker positive effects of temperature on wood decomposition under

114 low levels of precipitation may be the result of low wood moisture levels, limiting microbial activity $^{31,32}$ and selecting for drought-tolerant fungal species which have a reduced ability to decompose wood ${ }^{6}$. Given that temperature is predicted to increase globally ${ }^{33}$, our results

117 indicate that wood decomposition rates are likely to increase in the future. The strength of this increase will be modulated by current and future levels of precipitation and the emerging water balance of a site ${ }^{34}$. Decomposition rates were higher for angiosperms than for gymnosperms

120 (Table 1), which is consistent with results from a global meta-analysis and can be explained by differences in wood traits ${ }^{35}$. Results for standardized wooden dowels were similar to those for wood of native tree species (Extended Data Table 1). 
Insect access to deadwood affected decomposition, but this effect was contingent on climatic conditions (Table 1). The net effect of insects on decomposition was particularly high in the tropics (median $=3.9 \%$ mass loss per year, Fig. $1 \mathrm{~b}$ ). In contrast, effects were low in the temperate biome and even negative in the boreal biome (median of $0.9 \%$ and $-0.1 \%$, respectively; Fig. 1b). The net effect of insects generally increased with temperature, with effect size strongly mediated by precipitation (Table 1). At low levels of precipitation, temperature had only a minor influence on the net effect of insects. In contrast, at high levels of precipitation, temperature was a strong driver of the net effect of insects on decomposition (Fig. 2b; Extended Data Fig. 3b). At high temperatures, increasing precipitation increased the net effect of insects, while at low temperatures, increasing precipitation resulted in a negative net effect of insects. Thus, decomposition rates were higher when insects were excluded at low temperatures and high precipitation. Complex relationships between insects and climate are driving several mechanisms determining the net effect of insects on wood decomposition. First, wood-feeding termites are a key group of decomposers ${ }^{7,36}$, but are largely restricted to regions with high temperatures (Fig. 2b). Nevertheless, considerable variation in the net effect of insects also exists among sites where termites are present (Fig. 2b), underlining the importance of factors beyond termite occurrence. Second, temperature affects the metabolic rate of insects, increasing consumption and accelerating larval development directly ${ }^{19}$ as well as indirectly via enhanced food quality ${ }^{37}$. Third, insects can be negatively impacted by high wood moisture when precipitation is high and evaporation low, as is the case e.g. in humid boreal forests (Extended Data Fig. 3b), due to low aeration or high pathogen pressure ${ }^{38}$.

144 Conversely, moisture is a limiting factor at high temperatures, restricting the period of high insect activity to the rainy season ${ }^{39}$. Fourth, interactions of insects and microbes can decrease wood decomposition: Insects, for example, can introduce fungal species which do not contribute significantly to wood decomposition themselves, while suppressing other principal wood-decomposing fungi, thus lowering the overall decomposition rate ${ }^{26}$. In cold and humid regions, such biotic interactions might outweigh the effects of direct consumption, and lead to an overall negative net effect of insects on wood decomposition. 
151 Our findings indicate that wood decomposition is driven by the complex interplay of

152 temperature and precipitation with the decomposer community. Climate warming could

153 accelerate wood decomposition by increasing microbial activity and insect-mediated wood

154 decomposition, particularly where moisture is not limiting. However, increased drying as a

155 result of global change also could decrease deadwood decomposition. Our results support

156 that insect biodiversity loss has the potential to affect deadwood decomposition, but that

157 effects may vary regionally. To improve predictions of the functional effects of biodiversity loss,

158 more research is needed on how specific components of decomposer communities (i.e.,

159 biomass, species number, functional composition, species interactions) influence deadwood

160 decomposition ${ }^{7}$. Our work suggests that the strongest functional effects of changes in the

161 decomposer community will occur in regions with warm and humid climate, which should be

162 a particular focus of further research.

\section{Global carbon flux estimate}

164 To assess the role of deadwood decomposition in the global carbon cycle, we applied the 165 relationship between decomposition rates and local climate derived from our global experiment (Table 1) to a map of the global carbon currently stored in deadwood (Fig. 1a).

167 Since our experiment focused on small-diameter deadwood over three years, we adjusted decomposition rates to account for slower mass loss of large-diameter deadwood (for details see Methods and Supplementary Information section 2). We evaluated our relationship between decomposition rate and local climate against 157 independent empirical observations

171 from previous deadwood surveys ${ }^{28}$, spanning the full range of deadwood diameters $>7 \mathrm{~cm}$, time since tree death and climatic conditions. We obtained a good match of the results from our model to these independent data (Extended Data Fig. 4), suggesting our approach is robust.

175 We estimate that $10.9 \pm 3.2 \mathrm{Pg}$ carbon might be released from deadwood per year globally.

176 This suggests that deadwood decomposition could be an important flux in the global carbon 
177 cycle. Our estimate corresponds to $15-25 \%$ of the annual release of carbon from soils globally

178 (estimated to $50-75 \mathrm{Pg}$ carbon $\mathrm{a}^{-1}{ }^{29}$ ), and is $115 \%$ of the current anthropogenic carbon 179 emissions from fossil fuels (9.5 $\mathrm{Pg}$ carbon $\left.\mathrm{a}^{-1}{ }^{17}\right)$. We note, however, that not all carbon 180 released from deadwood through decomposition is emitted to the atmosphere, as parts are 181 immobilized in the biosphere or in soils ${ }^{40,41}$. Carbon release from deadwood is highest in 182 tropical biomes (10.2 Pg carbon $\mathrm{a}^{-1}$, Fig. 3a, Extended Data Table 3), where large deadwood 183 carbon pools and high decomposition rates coincide (Extended Data Fig. 5). Although 184 deadwood carbon stocks are also considerable in temperate and boreal biomes (amounting 185 to $35 \%$ of all carbon stored in deadwood globally), the climatic limitations for wood 186 decomposition as well as differences in decomposer communities (e.g., the absence of 187 termites) render annual carbon fluxes from deadwood much smaller (i.e., $0.44 \mathrm{Pg}_{\text {carbon } \mathrm{a}^{-1}}$

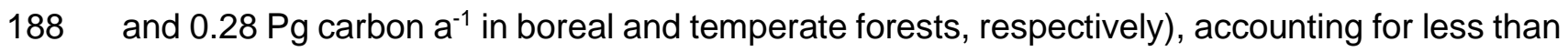
$1897 \%$ of the global carbon release from deadwood. Globally, the net effect of insects on wood 190 decomposition may result in a carbon flux of $3.2 \pm 0.9 \mathrm{Pg} \mathrm{a}^{-1}$, which represents $29 \%$ of the 191 total carbon released from deadwood (Fig. 3a; Extended Data Fig. 5).

192 Our global estimates are only a first step in a better quantification of the role of deadwood decomposition in the global carbon cycle. Uncertainties related to the underlying data, the statistical models, and other assumptions necessary for upscaling our experimental results were assessed in a global sensitivity analysis. This analysis bounded the uncertainty of global annual carbon release from deadwood and the net effect of insects at approximately $\pm 25 \%$ around the mean. Of the various sources of uncertainty that were considered, the underlying data on deadwood carbon stocks contributed most strongly to overall uncertainty (Fig. 3; Extended Data Table 2; Supplementary Information section 2). Our results suggest that global deadwood carbon cycle assessments could be improved by more accurately quantifying deadwood stocks in tropical forests. While the effects of wildfire were included in our 202 deadwood carbon map via the underlying inventory data, we did not explicitly consider 203 deadwood carbon release from fire. We note, however, that a large portion of the carbon 
204 stored in deadwood is not combusted in wildfires ${ }^{42,43}$. Further uncertainty results from our 205 experimental design: It cannot be ruled out that altered microclimatic conditions in cages 206 affected estimates of the net effect of insects derived from the comparison between closed 207 cage and uncaged treatments. Such a bias would lead to an underestimation of the net insect 208 effect in the tropics and an overestimation in the temperate zone (Supplementary Information 209 section 1). When the global annual net effect of insects on deadwood decomposition was 210 derived from the comparison of closed cage and open cage treatments, it still amounted to $2111.76 \mathrm{Pg}$ carbon. However, this value underestimates the true effect of insects due to reduced 212 insect colonization in the open cage treatment (Supplementary Information section 1; 213 Extended Data Fig. 2).

214 Our experiment highlights that deadwood and wood-decomposing insects play an important 215 role in the global carbon cycle. In contrast to the prevailing paradigm that insects generally 216 accelerate wood decomposition ${ }^{7}$, our results indicate that their functional role is more variable, 217 and is contingent on the prevailing climatic conditions. We conclude that ongoing climate 218 warming $^{33}$ will likely accelerate decomposition by enhancing the activity of microbes and 219 insects, an effect that will be particularly strong in regions where moisture is not limiting. To 220 robustly project the future of the forest carbon $\operatorname{sink}^{24,44}$, dynamic global vegetation models need to account for the intricacies of both deadwood creation (e.g., via natural disturbances) and deadwood decomposition. 
224 1. Pan, Y. et al. A large and persistent carbon sink in the world's forests. Science 333, 988-993 (2011).

2. Bradford, M. A. et al. Climate fails to predict wood decomposition at regional scales. Nat. Clim. Chang. 4, 625-630 (2014).

3. Chambers, J. Q., Higuchi, N., Schimel, J. P. J., Ferreira, L. V. \& Melack, J. M. Decomposition and carbon cycling of dead trees in tropical forests of the central Amazon. Oecologia 122, 380-388 (2000).

4. González, G. et al. Decay of aspen (Populus tremuloides Michx.) wood in moist and dry boreal, temperate, and tropical forest fragments. Ambio 37, 588597 (2008).

5. Stokland, J., Siitonen, J. \& Jonsson, B.

B. G. Biodiversity in dead wood. (Cambridge University Press, 2012).

6. Lustenhouwer, N. et al. A trait-based understanding of wood decomposition by fungi. Proc. Natl. Acad. Sci. U. S. A. 117, 1-8 (2020).

7. Ulyshen, M. D. Wood decomposition as influenced by invertebrates. Biol. Rev. Camb. Philos. Soc. 91, 70-85 (2016).

8. Pretzsch, H., Biber, P., Schütze, G., Uhl, E. \& Rötzer, T. Forest stand growth dynamics in Central Europe have accelerated since 1870. Nat. Commun. 5, 110 (2014).

9. Büntgen, U. et al. Limited capacity of tree growth to mitigate the global greenhouse effect under predicted warming. Nat. Commun. 10, 1-6 (2019).

10. Seidl, R. et al. Forest disturbances under climate change. Nat. Clim. Chang. 7, 395-402 (2017).

247 11. Hubau, W. et al. Asynchronous carbon sink saturation in African and 
Amazonian tropical forests. Nature 579, 80-87 (2020).

249

250

251

252

253

254

255

256

257

258

259

260

261

262

263

264

265

266

267

268

269

270

271

272

12. Portillo-Estrada, M. et al. Climatic controls on leaf litter decomposition across European forests and grasslands revealed by reciprocal litter transplantation experiments. Biogeosciences 13, 1621-1633 (2016).

13. Christenson, L. et al. Winter climate change influences on soil faunal distribution and abundance: implications for decomposition in the northern forest. Northeast. Nat. 24, B209-B234 (2017).

14. Keenan, T. F. et al. Increase in forest water-use efficiency as atmospheric carbon dioxide concentrations rise. Nature 499, 324-327 (2013).

15. Stephenson, N. L. et al. Rate of tree carbon accumulation increases continuously with tree size. Nature 507, 90-93 (2014).

16. Martin, A., Dimke, G., Doraisami, M. \& Thomas, S. Carbon fractions in the world's dead wood. Nat. Commun. 1-9 (2021). doi:10.31223/OSF.IO/SCX3Y

17. Friedlingstein, P. et al. Global carbon budget 2019. Earth Syst. Sci. Data 11, 1783-1838 (2019).

18. Ruiz-Peinado, R., Bravo-Oviedo, A., Lopez-Senespleda, E., Montero, G. \& Rio, M. Do thinnings influence biomass and soil carbon stocks in Mediterranean maritime pinewoods? Eur. J. For. Res. 132, 253-262 (2013).

19. Marshall, D. J., Pettersen, A. K., Bode, M. \& White, C. R. Developmental cost theory predicts thermal environment and vulnerability to global warming. Nat. Ecol. Evol. 4, 406-411 (2020).

20. Buczkowski, G. \& Bertelsmeier, C. Invasive termites in a changing climate: A global perspective. Ecol. Evol. 7, 974-985 (2017).

21. Diaz, S., Settele, J. \& Brondizio, E. Summary for policymakers of the global assessment report on biodiversity and ecosystem services of the 
Intergovermental Science-Policy Platform on Biodiversity and Ecosystem

274

275

276

277

278

279

280

281

282

283

284

285

286

287

288

289

290

291

292

293

294

295

296

297

Services. (IPBES, 2019).

22. van Klink, R. et al. Meta-analysis reveals declines in terrestrial but increases in freshwater insect abundances. Science 368, 417-420 (2020).

23. Seibold, S. et al. Arthropod decline in grasslands and forests is associated with landscape-level drivers. Nature 574, 671-674 (2019).

24. Harris, N. L. et al. Global maps of twenty-first century forest carbon fluxes. Nat. Clim. Chang. (2021). doi:10.1038/s41558-020-00976-6

25. Jacobsen, R. M., Sverdrup-Thygeson, A., Kauserud, H., Mundra, S. \& Birkemoe, T. Exclusion of invertebrates influences saprotrophic fungal community and wood decay rate in an experimental field study. Funct. Ecol. 32, 2571-2582 (2018).

26. Skelton, J. et al. Fungal symbionts of bark and ambrosia beetles can suppress decomposition of pine sapwood by competing with wood-decay fungi. Fungal Ecol. 45, 100926 (2020).

27. Wu, D., Seibold, S., Ruan, Z., Weng, C. \& Yu, M. Island size affects wood decomposition by changing decomposer distribution. Ecography (2020). doi:10.1111/ecog.05328

28. Harmon, M. E. et al. Release of coarse woody detritus-related carbon: A synthesis across forest biomes. Carbon Balance Manag. 15, 1-21 (2020).

29. Wall, D. H. et al. Global decomposition experiment shows soil animal impacts on decomposition are climate-dependent. Glob. Chang. Biol. 14, 2661-2677 (2008).

30. Gillooly, J. F., Brown, J. H., West, G. B., Savage, V. M. \& Charnov, E. L. Effects of size and temperature on metabolic rate. Science 293, 2248-2251 
(2001).

299

300

301

302

303

304

305

306

307

308

309

310

311

312

313

314

315

316

317

318

319

320

321

322

31. Baldrian, P. et al. Responses of the extracellular enzyme activities in hardwood forest to soil temperature and seasonality and the potential effects of climate change. Soil Biol. Biochem. 56, 60-68 (2013).

32. A'Bear, A. D., Jones, T. H., Kandeler, E. \& Boddy, L. Interactive effects of temperature and soil moisture on fungal-mediated wood decomposition and extracellular enzyme activity. Soil Biol. Biochem. 70, 151-158 (2014).

33. IPCC. Climate Change 2014: Synthesis Report. Contribution of Working Groups I, II and III to the Fifth Assessment Report of the Intergovernmental Panel on Climate Change. (IPCC, 2014).

34. Smyth, C. E., Kurz, W. A., Trofymow, J. A. \& CIDET Working Group. Including the effects of water stress on decomposition in the Carbon Budget Model of the Canadian Forest Sector CBM-CFS3. Ecol. Modell. 222, 1080-1091 (2011).

35. Weedon, J. T. et al. Global meta-analysis of wood decomposition rates: a role for trait variation among tree species? Ecol. Lett. 12, 45-56 (2009).

36. Griffiths, H. M., Ashton, L. A., Evans, T. A., Parr, C. L. \& Eggleton, P. Termites can decompose more than half of deadwood in tropical rainforest. Curr. Biol. 29, R118-R119 (2019).

37. Birkemoe, T., Jacobsen, R. M., Sverdrup-Thygeson, A. \& Biedermann, P. H. W. Insect-fungus interactions in dead wood. in Saproxylic Insects (ed. Ulyshen, M. D.) 377-427 (Springer, 2018).

38. Harvell, M. C. E. et al. Climate warming and disease risks for terrestrial and marine biota. Science 296, 2158-2162 (2002).

39. Berkov, A. Seasonality and stratification: neotropical saproxylic beetles respond to a heat and moisture continuum with conservatism and plasticity. in 
Saproxylic Insects (ed. Ulyshen, M. D.) 547-580 (2018).

324

325

326

327

328

329

330

331

332

333

334

335

336

337

40. Wang, C., Bond-Lamberty, B. \& Gower, S. T. Environmental controls on carbon dioxide flux from black spruce coarse woody debris. Oecologia 132, 374-381 (2002)

41. Peršoh, D. \& Borken, W. Impact of woody debris of different tree species on the microbial activity and community of an underlying organic horizon. Soil Biol. Biochem. 115, 516-525 (2017).

42. Campbell, J., Donato, D., Azuma, D. \& Law, B. Pyrogenic carbon emission from a large wildfire in Oregon, United States. J. Geophys. Res. Biogeosciences 112, 1-11 (2007).

43. Van Leeuwen, T. T. et al. Biomass burning fuel consumption rates: A field measurement database. Biogeosciences 11, 7305-7329 (2014).

44. McDowell, N. G. et al. Pervasive shifts in forest dynamics in a changing world. Science 368, eaaz9463 (2020). 
339 Figure 1 | Decomposition rates and insect effects per biome. a) Estimated carbon pools in 340 deadwood with diameter $>2 \mathrm{~cm}\left(\mathrm{Mg} \mathrm{C} \mathrm{ha}^{-1}\right)$ with 5 arc minutes spatial resolution and the 341 location of the 55 experimental sites (grey dots). b) Annual mass loss of deadwood of native 342 tree species when all decomposer groups have access (treatment uncaged) and c) difference 343 in annual mass loss between uncaged and closed cage treatments attributed to the net effect 344 of insects. Data show predicted values for both angiosperm and gymnosperm species at 55 and 21 sites, respectively, based on a Gaussian generalized linear mixed log-link model for 2533 logs with site-specific random effects and temperature, precipitation, treatment and host

347 type, as well as their interactions, as fixed effects (Table 1). Boxes represent data within the $25^{\text {th }}$ and $75^{\text {th }}$ percentile, black lines show medians, and whiskers extend to $1.5 \times$ the interquartile range. Note that the classification into biomes is shown for illustrative purposes, while the statistical model is based on continuous climate variables.

Figure 2 | Decomposition rates and net insect effects in climate space. a) Annual mass loss of deadwood of native tree species, considering all possible groups of decomposers (treatment uncaged) and b) annual mass loss attributed to insects (difference in mass loss between treatments uncaged and closed cage), relative to mean annual temperature and mean annual precipitation. Symbols indicate whether termites occur in the study areas. Points represent predicted values for angiosperm species at 55 sites and gymnosperm species at 21 sites based on a Gaussian generalized linear mixed log-link model for 2533 logs with sitespecific random effects and temperature, precipitation, treatment, host division, as well as their interactions, as fixed effects. Note that the lower sample size for gymnosperm species represents their global distribution.

Figure 3 | Global annual carbon release from deadwood and sensitivity analysis. a)

362 Annual carbon released $\left(\mathrm{Pg} \mathrm{C} \mathrm{a}{ }^{-1}\right)$ from deadwood per biome. Error bars indicate the uncertainty of the biome-specific estimate as determined by the sensitivity analysis. b) Relative 
364 contributions to the overall uncertainty of the global estimate of total carbon release from

365 deadwood decomposition. The color of the bars indicates uncertainty category. See Extended

366 Data Table 2 for a detailed description of each factor and an uncertainty assessment of the 367 net insect effect. 
370 log-link model for relative annual mass loss of wood of native tree species derived from a

371 global deadwood decomposition experiment. The model is based on data from closed cage 372 and uncaged treatments, comprising 2533 logs of native tree species from 55 sites. Fixed 373 effects were mean annual temperature and mean annual precipitation sum which were both centered and scaled, host tree type (angiosperm vs. gymnosperm) and treatment, as well as

375 their two- and three-way interactions, with site as random effect. Estimates and standard 376 errors are for temperature and precipitation transformed back to ${ }^{\circ} \mathrm{C}$ and $\mathrm{dm} \mathrm{a}^{-1}$. The main 377 effects for each variable are interpretable when the remaining variables are fixed at their 378 reference value $\left(15^{\circ} \mathrm{C}\right.$ and $\left.13 \mathrm{dm} \mathrm{a}^{-1}\right)$. A relative effect (i.e., exp(estimate)) of, for instance, 3790.989 means that for a temperature increase of $1^{\circ} \mathrm{C}$ with all other variables fixed (precipitation 380 at $13 \mathrm{dm} \mathrm{a}^{-1}$, host and treatment), the deadwood dry mass after one year would be $98.9 \%$ of 381 the mass without this change in temperature. This represents an additional mass loss of $1.1 \%$ 382 induced by a $1{ }^{\circ} \mathrm{C}$ increase in temperature. The marginal $\mathrm{R}^{2}$ of the model was 0.84 .

\begin{tabular}{|c|c|c|c|c|c|}
\hline Predictor & $\begin{array}{l}\text { Estimate } \\
{ }^{*} 10^{3}\end{array}$ & $\begin{array}{l}\text { Std.Error } \\
{ }^{*} 10^{3}\end{array}$ & z-value & $p$-value & $\begin{array}{l}\text { Relative effect and } \\
95 \% \text { confidence } \\
\text { interval }\end{array}$ \\
\hline Temperature (in ${ }^{\circ} \mathrm{C}-15$ ) & -11.009 & 3.021 & -3.644 & $<0.001$ & $0.989(0.983-0.995)$ \\
\hline Precipitation (in $\mathrm{dm} \mathrm{a}^{-1}-13$ ) & -3.135 & 3.322 & -0.944 & 0.345 & $0.997(0.990-1.003)$ \\
\hline Host: angiosperm & -150.477 & 22.506 & -6.686 & $<0.001$ & $0.860(0.823-0.899)$ \\
\hline Host: gymnosperm & -82.825 & 24.862 & -3.331 & 0.001 & $0.921(0.877-0.966)$ \\
\hline Treatment: uncaged vs. closed & -29.228 & 5.694 & -5.133 & $<0.001$ & $0.971(0.960-0.982)$ \\
\hline Temperature* ${ }^{*}$ recipitation & -0.565 & 0.401 & -1.408 & 0.159 & $0.999(0.999-1.000)$ \\
\hline Temperature*host & 5.016 & 1.250 & 4.014 & $<0.001$ & $1.005(1.003-1.007)$ \\
\hline Precipitation*host & -0.434 & 3.587 & -0.121 & 0.904 & $1.000(0.993-1.007)$ \\
\hline Temperature ${ }^{\star}$ treatment & -4.161 & 0.742 & -5.608 & $<0.001$ & $0.996(0.994-0.997)$ \\
\hline Precipitation*treatment & -5.236 & 0.923 & -5.675 & $<0.001$ & $0.995(0.993-0.997)$ \\
\hline Temperature*precipitation*host & 0.104 & 0.327 & 0.317 & 0.751 & $1.000(0.999-1.001)$ \\
\hline Temperature* precipitation ${ }^{*}$ treatment & -0.728 & 0.113 & -6.451 & $<0.001$ & $0.999(0.999-0.999)$ \\
\hline
\end{tabular}




\section{Experimental set-up}

We established 55 experimental sites in currently forested areas on six continents and three major biomes, spanning gradients in mean annual temperature from $-1.4^{\circ} \mathrm{C}$ to $27.0^{\circ} \mathrm{C}$ and mean annual precipitation from $2.90 \mathrm{dm} \mathrm{a}^{-1}$ to $33.86 \mathrm{dm}^{-1}$ (Fig. 1a). Sites were located in mature, closed-canopy stands of the dominant zonal forest type, and were selected so that structural and compositional characteristics were similar to those of natural forests. To quantify the net effect of insects on wood decomposition, we compared decomposition between uncaged wood accessible to all decomposers (treatment uncaged) and wood in closed cages excluding insects and other invertebrates (treatment closed cage; Extended Data Fig. 1). Cages excluded vertebrate and invertebrate decomposers, but for simplicity, and since insects comprise the functionally most important taxa, we refer to insects throughout the manuscript. To explore microclimatic effects of caging ${ }^{45}$, we added a third treatment of wood in cages with large openings (treatment: open cage), that allowed colonization by insects, but also provided similar microclimatic conditions as in the closed cage treatment (Supplementary Information section 1). Analyses across treatments showed that the most robust assessment of the net effect of insects on wood decomposition originated from the uncaged versus closed cage treatment, since cages had a significant effect on insect colonization, but not on microclimatic conditions, and thus decomposition rates were reduced in the open cage compared to the uncaged treatment (Supplementary Information section 1; Extended Data Fig. 2).

Cages measured $40 \times 40 \times 60 \mathrm{~cm}$ and were made of white polyester mesh with 1000 mesh per square inch. The honeycomb-shaped mesh holes had a width of approx. $0.5 \mathrm{~mm}$. Open cages had four rectangular openings measuring $3 \times 12 \mathrm{~cm}$ at both front sides and four rectangular openings measuring $10 \times 15 \mathrm{~cm}$ at the bottom, representing in total $6 \%$ of the surface area of the cage. Furthermore, open cages had a total of ten $12 \mathrm{~cm}$ slits at the top and long sides. Cages were placed on stainless steel mesh (0.5 mm mesh width), which had the 
410 same openings as the bottom side of the cages in the open cage treatment. The top layer of

411 fresh leaf litter was removed before the installation of treatments. The cages and layers of 412 steel mesh were both tightly fixed to the ground using tent pegs, to ensure that all deployed 413 logs had close contact with the soil and to allow water uptake and fungal colonization from the 414 soil. At each site, the three treatments were applied three times, i.e. three installations per 415 treatment per site, resulting in a total of nine installations per site (Extended Data Fig. 1). The 416 nine installations were arranged in a matrix of $3 \times 3$ with a spacing of $2 \mathrm{~m}$ between installations, 417 resulting in a total size of approx. $15 \mathrm{~m} \times 15 \mathrm{~m}$. Treatments were assigned randomly to each 418 of the nine locations within a site. The mean spore size and hyphae width of saprotrophic 419 fungal species (mean spore length and width: $8.9 \mu \mathrm{m}$ and $5.5 \mu \mathrm{m}^{46}$; hyphae width: 5-20 $420 \mu \mathrm{m}^{47,48}$ ) is by an order of magnitude smaller than the mesh width of our cages. Rhizomorphs, 421 i.e. linear aggregations of several hyphae, can be wider, but during mycelial growth each hypha extends apically rather than the whole rhizomorph ${ }^{49-51}$. Therefore, it is unlikely that the cages hampered fungal colonization. Data loggers recorded air temperature and humidity for the three treatments at nine sites (see Supplementary Information section 1 for details).

\section{Decomposition measurements}

Decomposition was measured as mass loss for unprocessed wood of three of the locally most abundant autochthonous tree species at each study site (Supplementary Table S3-1), as well as for standardized machined wooden dowels. Unprocessed wood of local tree species with the bark retained is more likely to be colonized by local insects and fungi than machined wood without bark ${ }^{45}$. The latter was used to compare decomposition based on a standardized substrate replicated across all sites. We cut wood of local tree species $(\sim 3 \mathrm{~cm}$ in diameter and $\sim 60 \mathrm{~cm}$ in length) from either branches or stems of young healthy trees without visible signs of insect or fungal activity. One $5 \mathrm{~cm}$ long section was cut from each end of all fresh logs, and the fresh mass of both the cut sections and the resulting $50 \mathrm{~cm}$ logs were weighed. The dry mass of all $5 \mathrm{~cm}$ sections was measured after drying them at $40^{\circ} \mathrm{C}$ until no further mass loss was observed. We calculated the dry mass of the respective $50 \mathrm{~cm}$ logs as dry mass $50 \mathrm{~cm}=$ 
437 (fresh mass $50 \mathrm{~cm} /$ fresh mass $5 \mathrm{~cm}$ ) x dry mass $5 \mathrm{~cm}$. Each installation received three 50

$438 \mathrm{~cm}$ long logs of each of the three local tree species and one (closed cage) or two (open cage 439 and uncaged) standardized wooden dowels, giving a total of 96 logs at each site. Standardized 440 dowels (3 cm in diameter, $50 \mathrm{~cm}$ in length) were dried machined dowels of Fagus sylvatica $\mathrm{L}$. 441 without bark. They were obtained from a single producer in Germany and were then distributed 442 to all sites. Initial dry mass of the dowels was measured directly after drying. All logs and 443 dowels were labeled using numbered plastic tags and assigned randomly to one of the nine 444 installations.

445 The experiment was established between March 2015 and August 2016 depending on the seasonality of each site. After approximately one, two and three years, one of the three

447 installations of each treatment per site were randomly selected and collected to measure wood 448 decomposition. That is, all logs from one uncaged, one closed cage and one open cage 449 treatment were collected per site at the same time. We chose this approach because the 450 maximum distance between installations was $6 \mathrm{~m}$ and thus within-site variation was expected 451 to be rather low. Moreover, we wanted to ensure that the same number of logs could be 452 sampled per treatment and year and failure of cages over time would have resulted in an 453 unbalanced number of logs per treatment. Due to loss of some cages, high decomposition 454 rates at some sites and logistical restrictions, we were not able to maintain the experiment for 455 three years at all sites (Supplementary Table S3-1). Litter and soil attached to the wood was 456 removed carefully upon collection, while fungal fruit bodies were retained. We assessed insect 457 colonization (presence/ absence) for each log based on visible feeding marks, larval tunnels, 458 or exit holes for $3430(91 \%)$ of the analyzed logs. The collected logs were dried at $40^{\circ} \mathrm{C}$ until 459 mass remained constant and dry mass was measured. At sites where termites were present, 460 logs were burned to account for soil that might have been carried into the wood by these 461 insects ${ }^{45}$. This involved placing one sample at a time onto a steel pan atop a propane burner, 462 and an electrical fan was used to provide aeration and to blow away ash. The residual soil 463 was weighed and its mass subtracted from the dry mass of the wood. 
All statistical analyses were performed in $\mathrm{R}$ version $4.0 .4^{52}$. For each site, we derived

466

467

468

469

470

471

472

473

474

475

476

477

478

479

480

481

482

483

484

485

486

487

488

489

490 information on average climate conditions from WorldClim (v2) $)^{53}$, specifically BIOMOD variables 1 (mean annual temperature) and 12 (mean annual precipitation sum). We modelled relative wood mass loss of local tree species over time using a Gaussian generalized linear mixed model (function glmer in package $/ m e 4^{54}$, version 1.1 .26 ) with log link. Dry mass of each individual log at time $t$ served as the response variable and log-transformed initial dry mass ( $t$ $=0$ ) was used as an offset term. For each increase of one time unit (one year), the relative reduction is given by $\exp (\beta)$. Note that the model contained no intercept due to the constraint $\exp (\beta)^{0}=1$. The rate $\exp (\beta)$ was modelled depending on treatment (i.e. closed cage versus uncaged), and host type (angiosperm versus gymnosperm), as well as mean annual temperature $\left[{ }^{\circ} \mathrm{C}\right]$ and mean annual precipitation sum $\left[\mathrm{dm} \mathrm{a}^{-1}\right]$. Temperature and precipitation were centered and scaled before modelling, but model coefficients were then backtransformed for ease of interpretation. Reference values for temperature and precipitation were $15^{\circ} \mathrm{C}$ and $13 \mathrm{dm} \mathrm{a}^{-1}$, respectively. The model included site-specific random time slopes to deal with clustered observations. Based on this model, we computed the fitted annual relative mass loss (in \%) for each site considering temperature and precipitation. This was done separately for angiosperm and gymnosperm wood for all sites where respective tree species were present. Note that differences in decomposition between tree species could not be tested but were subsumed in the random slope of the site, since most tree species occurred at only a few sites (Supplementary Table S3-1).

To evaluate potential differences in decomposition rates between the wood of native tree species and standardized wood samples, we estimated the same model for standardized wooden dowels. Further models were fitted to evaluate potential microclimatic effects of the cages on decomposition rates and insect colonization. This included one model for wood decomposition of native tree species for the treatments closed cage versus open cage, and one model comparing wood decomposition between all three treatment levels (uncaged, 
closed cage and open cage) using a post-hoc test. A binomial generalized linear mixed model

492 was fitted for insect colonization and linear mixed models were fitted for mean daily 493 temperature and mean daily relative humidity. Post-hoc tests were applied to these models 494 for comparisons among the three treatments.

\section{Estimation of global carbon fluxes from deadwood decomposition}

496 To estimate the global carbon flux from deadwood decomposition, we fitted an additive beta 497 regression model (function gam with family betar in package $m g c v^{55}$, version 1.8 ) to site 498 specific predicted relative annual mass loss using temperature and precipitation as predictors, 499 separately for angiosperm and gymnosperm. Based on predicted relative annual mass loss 500 for the uncaged treatment, this model was used to predict total deadwood carbon release 501 globally (i.e. attributable to all kinds of decomposers). To quantify the amount of carbon

502 released from deadwood due to the net effect of insects, we applied the beta regression model 503 to predicted relative annual mass loss for the closed cage treatment and calculated it as 504 carbon release uncaged $_{\text {- carbon release }}$ closed cage.

505 We applied this model to a spatially-explicit global map of carbon stored in deadwood of 506 angiosperms and gymnosperms, which we synthesized from empirical and remote sensing

507 data sets. We used mean annual temperature and mean annual precipitation sum from 508 WorldClim (v2) ${ }^{53}$ as predictor data. The GlobBiom (http://globbiomass.org) data set provides 509 high-resolution estimates of forest biomass based on Earth Observation data within the 510 framework of ESA's GlobBiomass project. We used the GlobBiom aboveground biomass layer 511 (i.e., stem, bark, and branch compartments) for the reference year 2010, and aggregated 512 information to the base resolution of WorldClim, i.e., 5 arc minutes (Extended Data Fig. 6a).

513 We extended the aboveground biomass information provided by GlobBiom to total live carbon 514 (including roots) by applying biome-specific root expansion factors ${ }^{56}$ and biome-specific 515 biomass to carbon conversion factors between 0.47 and $0.49^{16}$ (Extended Data Fig. 6b). The 516 delineation of forest biomes was taken from $\mathrm{FAO}^{57}$. 
517 We calculated deadwood carbon stocks at a spatial grain of 5 ' by relating deadwood carbon

518 stocks to total live carbon stocks (i.e., deadwood carbon fraction). To quantify regional 519 deadwood carbon fractions, we used data compiled by Pan et al. ${ }^{1}$, which are based on forest 520 inventory data and represent the most comprehensive analysis of global forest carbon stocks available to date. We reanalyzed their data set and amended it with data from the FAO Forest Assessment Report ${ }^{58}$ where values were missing (Extended Data Table 3). Our estimate of global deadwood carbon stocks therefore reflects local differences in forest productivity, mortality, and land management. The values reported in Pan et al. ${ }^{1}$ defined deadwood as "all non-living woody biomass not contained in the litter, either standing, lying on the ground, or in the soil" with a diameter $>10 \mathrm{~cm}$. We extended our deadwood carbon pool estimate to include all deadwood $>2 \mathrm{~cm}$ diameter by applying an expansion factor based on empirical allometric relationships ${ }^{59}$. Our global map of deadwood (Fig. 1a) thus represents the total amount of carbon stored in standing and downed deadwood with a diameter of $>2 \mathrm{~cm}$ for the reference year 2010.

To differentiate between deadwood of angiosperms and gymnosperms, we used the proportion of broad- and needle-leaved biomass derived from the global land cover product GLCNMO2013 ${ }^{60}$. The resolution of GLCNMO2013 is $1 / 240$ degree (i.e., each of our 5' cells contains 400 land cover pixels), and it provides information on 20 land cover classes. We reclassified these to "Broadleaved", "Needle-leaved", and "Mixed forest", and aggregated to 5 ' cells for each of the three forest types. The final proportion of each group was calculated assuming that carbon in mixed forests was equally distributed between angiosperms and gymnosperms (Extended Data Fig. 6c).

The experimental sites were chosen to span the global bioclimatic space inhabited by forests.

540 Nonetheless, gaps remained in very cold and dry climatic conditions for both angiosperm and gymnosperm species as well as in very warm and wet climatic conditions for gymnosperm tree

542 species. We constrained the application of our decomposition models to the climate space 543 covered by the experiment to avoid extrapolation beyond our data. Specifically, we defined 
544 the bioclimatic space for robust predictions via a convex hull around experimental sites in

545 temperature - precipitation space (using a buffer of $3^{\circ}$ and $3 \mathrm{dm}$, respectively). Subsequently,

546 climatic conditions outside that convex hull were mapped to the nearest point within the hull

547 in our modelling (Extended Data Fig. 7).

548 Our statistical model was derived from deadwood samples with a diameter of $\sim 3 \mathrm{~cm}$, and thus

549 overestimates annual decomposition rates when applied over the full diameter range of

550 deadwood (Supplementary Information section 2). To address this potential bias, we used a

551 conversion factor relating wood mass loss of fine woody debris (FWD, $<10 \mathrm{~cm}$ in diameter)

552 to coarse woody debris (CWD, $>10 \mathrm{~cm}$ ). We based our conversion factor on data from eleven

553 peer-reviewed studies reporting data on both CWD and FWD decomposition, covering all

554 major global biomes (Supplementary Table S2-1). As the relationship of CWD mass loss rate

555 over FWD mass loss rate was robust across different climates, we used its median value

556 (0.53) in our upscaling. An evaluation of the final deadwood decomposition rates used for

557 deriving a first global estimate of the carbon flux from deadwood was performed against

558 independent data from 157 observations compiled by Harmon et al. ${ }^{28}$. This evaluation against

559 independent data indicated good agreement across all major biomes and diameter classes

560 (Extended Data Fig. 4).

561 Finally, we accounted for the slower carbon release from standing deadwood relative to

562 downed woody debris, particularly in dry regions of the boreal and temperate biome. Based

563 on a wood decomposition data set for standing and downed deadwood across several decay

564 classes for the temperate and boreal biome ${ }^{61}$, we estimated decomposition of standing 565 deadwood to be $33-80 \%$ slower compared to lying logs. This is consistent with a detailed 566 analysis for temperate forests in Switzerland ${ }^{62}$ that found a slowdown of $42 \%$. In the tropics, 567 however, decomposition rates of standing trees have the same or sometimes even higher 568 decomposition rates as downed trees ${ }^{3,63,64}$. We assumed a reduction of decomposition rates by $50 \%$ for standing deadwood in temperate and boreal forests, and no reduction in the tropical 
570 biome in our upscaling. Based on large-scale inventories ${ }^{65-69}$ we estimated the proportion of 571 standing deadwood on total deadwood as $25 \%$ and $30 \%$ for the boreal and temperate biome, 572 respectively.

573 Our global estimate of the carbon fluxes of deadwood decomposition required a number of 574 analytical steps and assumptions, each of which is associated with uncertainties. These can 575 be classified into uncertainties related to deadwood carbon stocks ("Data uncertainties"), 576 uncertainties related to the statistical modelling of deadwood decomposition ("Model 577 uncertainties"), and uncertainties in the upscaling of model results to the global scale ("Scaling 578 uncertainties"). To assess the robustness of our estimate, we performed a global sensitivity 579 analysis ${ }^{48}$ where we selected three to four indicators for each of these three categories of 580 uncertainty, and estimated their influence on the overall result. For each of the ten indicators 581 analyzed in total, we selected either a single alternative (e.g., use of the standardized dowels instead of native species) or an upper and lower bound around the default value based on available data or indicator-specific assumptions (Extended Data Table 2). With regard to data uncertainty, we investigated uncertainties associated with the GlobBiom data set used as important data basis here, the deadwood carbon pool estimates ${ }^{1}$, and the expansion factors used to derive total biomass from aboveground biomass ${ }^{56}$. Model uncertainties were considered by employing alternative models using the $97.5^{\text {th }}$ and $2.5^{\text {th }}$ percentile of parameter values for fixed effects of the original model, an additional model accounting for potential microclimatic effects of cages (i.e., using the open cage instead of the uncaged treatment), and a model based on results for the standardized dowels (instead of the native tree species).

591 Lastly, scaling uncertainties were addressed by analyzing alternative expansion factors to 592 include deadwood $<10 \mathrm{~cm}$, varying relationships between FWD and CWD decay rate, 593 alternative assumptions regarding the proportion and decay rate of standing deadwood, and 594 the treatment of regions outside of the climate envelope covered by our experiment (see 595 Extended Data Table 2 for details). All factor levels of all indicators were allowed to vary 596 simultaneously, resulting in a total of 4860 estimates for annual deadwood carbon release and 
597 the net effects of insects. The relative influence of each indicator on total uncertainty was 598 derived by means of ANOVA, determining the percent of variance explained by each factor. 599 The contribution at the level of uncertainty categories was derived as the sum of the factors 600 per category. The uncertainty range for the global annual deadwood carbon release estimated 601 from this global sensitivity analysis was $\pm 3.14 \mathrm{Pg}$, and the net effect of insects varied by \pm 0.88 $602 \mathrm{Pg}$ carbon. Data uncertainty was identified as the most important factor ( $40 \%)$, but both 603 model and scaling uncertainty were also highly influential, each contributing $25-30 \%$ to the 604 overall variation in the results (Extended Data Table 2). 
606

607

608

609

610

611

612

613

614

615

616

617

618

619

620

621

622

623

624

625

626

627

628

629

45. Ulyshen, M. D. \& Wagner, T. L. Quantifying arthropod contributions to wood decay. Methods Ecol. Evol. 4, 345-352 (2013).

46. Bässler, C., Heilmann-Clausen, J., Karasch, P., Brandl, R. \& Halbwachs, H. Ectomycorrhizal fungi have larger fruit bodies than saprotrophic fungi. Fungal Ecol. 17, 205-212 (2015).

47. Ryvarden, L. \& Gilbertson, R. L. The Polyporaceae of Europe. (Fungiflora, 1994).

48. Eriksson, J. \& Ryvarden, L. The Corticiaceae of North Europe Part 1-8. (Fungiflora, 1987).

49. Boddy, L., Hynes, J., Bebber, D. P. \& Fricker, M. D. Saprotrophic cord systems. dispersal mechanisms in space and time. Mycoscience 50, 9-19 (2009).

50. Moore, D. Fungal Morphogenesis. (Cambridge University Press, 1998).

51. Clemencon, H. Anatomy of the Hymenomycetes. (Universtity of Lausanne, 1997).

52. R Core Team. R: A language and environment for statistical computing. (2020).

53. Fick, S. E. \& Hijmans, R. J. WorldClim 2: new 1-km spatial resolution climate surfaces for global land areas. Int. J. Climatol. 37, 4302-4315 (2017).

54. Bates, D., Maechler, M., Bolker, B. \& Walker, S. Fitting linear mixed-effects models using Ime4. J. Stat. Softw. 67, 1-48 (2015).

55. Wood, S. N. Generalized Additive Models: an introduction with R (2nd edition). (Chapman and Hall/CRC, 2017).

56. Robinson, D. Implications of a large global root biomass for carbon sink 
estimates and for soil carbon dynamics. Proc. R. Soc. B Biol. Sci. 274, 27532759 (2007).

57. Food and Agriculture Organization. Global ecological zones for FAO forest reporting: 2010 Update, Forest Resource Assessment Working Paper. (Food and Agriculture Organization, 2012).

58. Food and Agriculture Organization. Global Forest Resources Assessment 2015. (Food and Agriculture Organization, 2016).

59. Müller-Using, S. \& Bartsch, N. Decay dynamic of coarse and fine woody debris of a beech (Fagus sylvatica L.) forest in Central Germany. Eur. J. For. Res. 128, 287-296 (2009).

60. Kobayashi, T. et al. Production of global land cover data - GLCNMO2013. J. Geogr. Geol. 9, 1 (2017).

61. Harmon, M. E., Woodall, C. W., Fasth, B., Sexton, J. \& Yatkov, M. Differences between standing and downed dead tree wood density reduction factors: $A$ comparison across decay classes and tree species. U.S. Department of Agriculture, Forest Service, Northern Research Station, Research Paper NRS15 (2011).

62. Hararuk, O., Kurz, W. A. \& Didion, M. Dynamics of dead wood decay in Swiss forests. For. Ecosyst. 7, (2020).

63. Gora, E. M., Kneale, R. C., Larjavaara, M. \& Muller-Landau, H. C. Dead wood necromass in a moist tropical forest: stocks, fluxes, and spatiotemporal variability. Ecosystems 22, 1189-1205 (2019).

64. Hérault, B. et al. Modeling decay rates of dead wood in a neotropical forest. Oecologia 164, 243-251 (2010).

654 65. Thünen-Institut für Waldökosysteme. Der Wald in Deutschland - Ausgewählte 

und Landwirtschaft, 2014).

66. Puletti, N. et al. A dataset of forest volume deadwood estimates for Europe. Ann. For. Sci. 76, 1-8 (2019).

67. Richardson, S. J. et al. Deadwood in New Zealand's indigenous forests. For. Ecol. Manage. 258, 2456-2466 (2009).

68. Shorohova, E. \& Kapitsa, E. Stand and landscape scale variability in the

69. Szymañski, C., Fontana, G. \& Sanguinetti, J. Natural and anthropogenic influences on coarse woody debris stocks in Nothofagus-Araucaria forests of 666 northern Patagonia, Argentina. Austral Ecol. 42, 48-60 (2017).

\section{Data availability}

668 Raw data from the global deadwood experiment, our global map of deadwood carbon and our 669 map of predicted decomposition rates are publicly available from figshare 670 https://figshare.com/s/ffc39ee0724b11bf450c (doi: 10.6084/m9.figshare.14545992).

\section{Code availability}

672 An annotated $\mathrm{R}$ code including the data needed to reproduce the statistical analyses, global 673 estimates, and sensitivity analysis is publicly available from figshare $674 \mathrm{https}: / /$ figshare.com/s/ffc39ee0724b11bf450c (doi: 10.6084/m9.figshare.14545992).

\section{Acknowledgments}

676 We thank the administration of the Bavarian Forest National Park for financing the setup of 677 the experiment and all members of the local teams for their contribution in the field and 
678 laboratory. We especially thank David Blair who operated the site in Victoria, Australia, until

679 his unexpected death in 2019. We thank Bodo von Rentzel, Jörg Ganzhorn, Axel Gruppe,

680 Mark Harmon, Sandra Muller and Sandra Irwin, Makiling Center for Mountain Ecosystems,

681 University of the Philippines Los Banos, the Ministerio del Ambiente de Ecuador, the Instituto 682 Nacional de Biodiversidad de Ecuador and the foundation "Nature and Culture International" 683 for their support. S.S. was supported by the German Academic Exchange Service (DAAD) 684 with funds from the German Federal Ministry of Education and Research and the People 685 Programme of the European Union (Marie Curie Actions; grant number 605728). N.F. was 686 supported by the German Research Foundation (FA925/7-1, FA925/11-1).

\section{Author information}

688 Affiliations

689 Ecosystem Dynamics and Forest Management Group, Technical University of Munich, 690 Freising, Germany

691 S. Seibold, R. Seidl \& W. Rammer

692 Berchtesgaden National Park, Berchtesgaden, Germany

693 S. Seibold \& R. Seidl

694 Epidemiology, Biostatistics, and Prevention Institute, University of Zurich, Zurich, 695 Switzerland

696 T. Hothorn

697 Field Station Fabrikschleichach, University of Würzburg, Rauhenebrach, Germany

698 J. Müller, J. Lorz \& S. Thorn

699 Southern Research Station, USDA Forest Service, Athens, GA, USA

700 M. D. Ulyshen

701 Fenner School of Environment and Society, The Australian National University,

702 Canberra, ACT, Australia

703 D. B. Lindenmayer

704 Department of Biogeography, University of Bayreuth, Bayreuth, Germany

705 Y. P. Adhikari

706 Department of Disturbance Ecology, University of Bayreuth, Bayreuth, Germany

707 Y. P. Adhikari

708 Instituto de Ecología Regional, CONICET-Universidad Nacional de Tucumán, Yerba

709 Buena, Tucumán, Argentina 
710 R. Aragón \& R. D. Fernández

711 Department of Animal Ecology and Tropical Biology, University of Würzburg,

712 Würzburg, Germany

713 S. Bae

714 Laboratory of Environmental Microbiology, Institute of Microbiology of the Czech

715 Academy of Sciences, Praha, Czech Republic

716 P. Baldrian

717 Agricultural and Natural Resources Research Centre of Mazandaran, Sari, Iran

718 H. Barimani Varandi

719 Lancaster Environment Centre, Lancaster University, Lancaster, UK

720 E. Berenguer \& J. Barlow

721 Universidade Federal de Lavras, Lavras, Brazil

722 J. Barlow

723 Department of Biodiversity Conservation, Goethe-University Frankfurt, Frankfurt,

724 Germany

725 C. Bässler

726 Bavarian Forest National Park, Grafenau, Germany

727 J. Müller, C. Bässler \& C. Heibl

728 CIRAD, UMR Ecologie des Forêts de Guyane (EcoFoG), AgroParisTech, CNRS, INRA,

729 Universite des Antilles, Universite de Guyane, Kourou, France

730 J. Beauchêne

731 Environmental Change Institute, University of Oxford, Oxford, UK

732 E. Berenguer

733 Grassland Vegetation Lab, Federal University of Rio Grande do Sul, Brazil

734 R. S. Bergamin

735 Faculty of Environmental Sciences and Natural Resource Management, Norwegian

736 University of Life Sciences, Aas, Norway

737 A. Sverdrup-Thygeson \& T. Birkemoe

738 Institute of Ecology and Botany, Centre for Ecological Research, Vácrátót, Hungary

739 G. Boros

740 Department of Zoology and Animal Ecology, Szent István University, Gödöllő,

741 Hungary

742 G. Boros

743 Animal Ecology, University of Marburg, Marburg, Germany

744 R. Brandl

745 École d'Ingénieurs de Purpan, Université de Toulouse, Toulouse, France

746 E. Cateau \& H. Brustel 
747 Ecosystem Science and Management Program, University of Northern British

748 Columbia, Terrace, B.C., Canada

749 P. J. Burton

750 Biological Sciences, University of Toronto Scarborough, Toronto, ON, Canada

751 M. W. Cadotte

752 Laboratory of Applied Ecology, University of Abomey-Calavi, Benin

753 Y. T. Cakpo-Tossou

754 Department of Ecology, University of Granada, Granada, Spain

755 J. Castro

756 Réserves Naturelles de France, Dijon, France

757 E. Cateau

758 Royal Alberta Museum, Edmonton, Alberta, Canada

759 T. P. Cobb

760 Conservation Ecology, University of Marburg, Marburg, Germany

$761 \quad$ N. Farwig

762 Science and Engineering Faculty, Queensland University of Technology, Brisbane,

763 Australia

764 J. Firn

765 Centre for the Environment, Institute for Future Environments, Brisbane, Australia

766 J. Firn

767 Forest Research Institute Malaysia, Malaysia

768 K. Gan

769 International Institute of Tropical Forestry, USDA Forest Service, San Juan, PR, USA

770 G. González

771 Swiss Federal Research Institute WSL, Birmensdorf, Switzerland

772 M. M. Gossner \& T. Lachat

773 Evolutionary Zoology, University of Salzburg, Salzburg, Austria

774 J. C. Habel

775 Natural Resources Canada, Canadian Forest Service, Quebec, Canada

776 C. Hébert

777 Eurofins Ahma Oy, Oulu, Finland

778 O. Heikkala

779 Department of Plant Systematics, University of Bayreuth, Bayreuth, Germany

780 A. Hemp \& C. Hemp

781 Department of Wildlife, Fish, and Environmental Studies, Swedish University of

782 Agricultural Sciences, Umeå, Sweden

783 J. Hjältén 
784 Applied Landscape Ecology, Chuo University, Tokyo, Japan

785 S. Hotes

786 School of Forest Sciences, University of Eastern Finland, Joensuu, Finland

787 J. Kouki

788 School of Agricultural, Forest and Food Sciences, Bern University of Applied

789 Sciences, Zollikofen, Switzerland

790 T. Lachat

791 CAS Key Laboratory for Plant Diversity and Biogeography of East Asia, Kunming

792 Institute of Botany, Chinese Academy of Sciences, Kunming, China

793 J. Liu \& Y. Luo

794 ECNU-Alberta Joint Lab for Biodiversity Study, Tiantong National Station for Forest

795 Ecosystem Research, East China Normal University, Shanghai, China

796 Y. Liu

797 Institute of Biological Sciences, University of the Philippines Los Banos, Laguna,

798 Philippines

799 D. M. Macandog

800 Department of Thermodynamics, Universidad Nacional del Nordeste, Resistencia,

801 Argentina

802 P. E. Martina

803 Tropical Forests and People Research Centre, University of the Sunshine Coast,

804 Maroochydore, QLD, Australia

805 S. A. Mukul

806 Forest Ecosystem Monitoring Laboratory, National University of Mongolia,

807 Ulaanbaatar, Mongolia

808 B. Nachin \& B. Suran

809 School of Environment and Science, Griffith University, Nathan, QLD, Australia

810 K. Nisbet

811 School of Biological, Earth and Environmental Sceinces, University College, Cork,

812 Ireland

813 J. O'Halloran

814 Edge Hill University, Ormskirk, Lancashire, UK

815 A. Oxbrough

816 Institute of Forestry, Tribhuvan University, Pokhara, Nepal

817 J. Pandey

818 Institute of Evolution, University of Haifa, Haifa, Israel

819 T. Pavlíček

820 Scion (New Zealand Forest Research Institute), Christchurch, New Zealand 
822 School of Forestry, University of Canterbury, Christchurch, New Zealand

823 S. M. Pawson

824 Institute of Zoology, University of Hamburg, Hamburg, Germany

825 J. S. Rakotondranary

826 Faculté des Sciences, Université d'Antananarivo, Antananarivo, Madagascar

827 J. S. Rakotondranary

828 Tropical Biodiversity and Social Enterprise, Fort-Dauphin, Madagascar

829 J. Ramanamanjato

830 Departamento de Ecologia, Universidade Estadual Paulista, Rio Claro, SP, Brazil

831 L. C. Rossi

832 Ecology group, University Erlangen-Nuremberg, Erlangen, Germany

833 J. Schmidl

834 H.J. Andrews Experimental Forest, Blue River, OR, USA

835 M. Schulze

836 Environmental and Conservation Sciences, Murdoch University, Melville, WA,

837 Australia

838 S. Seaton

839 Environmental Futures Research Institute, Griffith University, Nathan, QLD, Australia.

840 M. J. Stone \& N. E. Stork

841 Ashoka Trust for Research in Ecology and the Environment, Bangalore, India

842 G. Thyagarajan

843 School of Plant Sciences, University of Tasmania, Australia

844 T. J. Wardlaw

845 Terrestrial Ecology Research Group, Technical University of Munich, Freising,

846 Germany

847 W. W. Weisser

848 EcoBank Team, National Institute of Ecology, Seocheon-gun, Republic of Korea

849 S. Yoon

850 College of Forestry, Beijing Forestry University, Beijing, China

$851 \quad$ N. Zhang

852

853 Contributions

854 S.S., J.M., R.S. perceived the idea of this manuscript. S.S., J.M. and M.U. designed the 855 experiment. S.S., J.L., W.R., M.U., Y.A., R.A., S.B., H.Ba., J.Ba., J.Be., E.B., R.Be., T.B., G.B., 
856 H.Br., P.Bu., M.C., Y.C., J.C., E.C., T.C., N.F.,R.F., J.F., K.G., G.G., J.H., C.Heb., O.H., A.H.,

857 C.H., J.H., S.H., J.K., T.L., D.L., J.L., Y.Li., Y.Lu., D.M., P.M., S.M., B.N., K.N., J.O., A.O., 858 T.P., S.P., J.Rak., J.Ram., L.R., M.Sc., S.Sea., M.St., N.S., B.S., A.S., G.T., T.W., S.Y., N.Z., 859 J.M collected data. S.S., T.H., and W.R. analyzed the data. S.S., J.M., R.S. and W.R. wrote 860 the first manuscript draft with significant inputs from M.U., M.C. and D.L., and finalized the 861 manuscript. All authors commented on the manuscript.

862 Corresponding author

863 Correspondence to Sebastian Seibold sebastian.seibold@tum.de

864 Ethics declarations

865 Competing interests

866 The authors declare no competing interests.

867 Additional Information

868 Supplementary Information This file contains supplementary information about methods, 869 descriptions of supplementary analyses and a detailed discussion addressing methodological 870 challenges. 
871 Extended Data Table 1 | Supporting analyses of drivers of wood decomposition. Results

872 from Gaussian generalized linear mixed log-link models for relative annual mass loss of a)

873 standardized wooden dowels comparing the treatments uncaged versus closed cage (415

874 logs from 55 sites) and b) wood of native tree species comparing the treatments open cage 875 and closed cage 2522 logs from 55 sites). Models include mean annual temperature and mean 876 annual precipitation sum which were both centered and scaled, host tree type (angiosperm 877 vs. gymnosperm; in model b only) and treatment, as well as their two- and three-way 878 interactions, as fixed effects and site as the random effect. Estimates and standard error are 879 for temperature and precipitation transformed back to ${ }^{\circ} \mathrm{C}$ and $\mathrm{dm} \mathrm{a}^{-1}$. The main effects of each 880 variable is interpretable when the remaining variables are fixed at their reference value $\left(15^{\circ} \mathrm{C}\right.$ 881 and $\left.13 \mathrm{dm} \mathrm{a}^{-1}\right)$.

882 Extended Data Table 2 | Uncertainty in global carbon fluxes from deadwood 883 decomposition, determined in a global sensitivity analysis. Important factors per 884 uncertainty category were selected and allowed to vary simultaneously, resulting in a total of 8854860 analyzed combinations. The uncertainty of total annual deadwood carbon released and 886 of the net effect of insects was calculated as the standard deviation over all combinations for 887 each factor, with all other factors fixed to their default value. Similarly, the uncertainty per 888 category was calculated over all combinations within a category, with all factors from other 889 categories fixed to the default value. The relative contribution of each factor to overall 890 uncertainty was derived by means of an ANOVA, estimating the percent of variance explained 891 for each factor. The contribution at the level of uncertainty categories is the sum of the 892 respective factors in each category. $\mathrm{Cl}=$ confidence interval; $\mathrm{FWD}=$ fine woody debris; $\mathrm{CWD}=$ 893 coarse woody debris; SWD= standing woody debris; $\mathrm{DWD}=$ downed woody debris.

894 Extended Data Table 3 | Comparison of global carbon stock estimates and results for

895 biomes. a) Global estimates of total live carbon and carbon in deadwood $(>10 \mathrm{~cm})$ from Pan 896 et al. ${ }^{1}$ compared with estimates obtained in this study $(>2 \mathrm{~cm})$ in Pg. Numbers in brackets 897 indicate the difference in percent. Note that Pan et al. ${ }^{1}$ defined biomes at country level while 
898 we here define biomes using the FAO Global Ecological Zones. Differences between these 899 biome definitions are especially significant for the temperate biome, as temperate parts of 900 Russia and Canada are included in the boreal biome in Pan et al. ${ }^{1}$, while we here divide Russia 901 and Canada into boreal and temperate regions. Furthermore, missing and unrealistic 902 deadwood carbon stocks for a number of areas (specifically Japan, South Korea, China, 903 Australia, and Alaska) in Pan et al. ${ }^{1}$ were complemented with data from the FAO Forest 904 Assessment Report ${ }^{58}$ in this study, which contributes to higher deadwood carbon estimates 905 relative to Pan et al. ${ }^{1}$. b) annual deadwood carbon release and net insect effect per biome (in $906 \mathrm{Pg}$ ), and calculated residence time of deadwood carbon (years). 
908 Extended Data Figure 1| Arrangement of installations per site and treatments. a) Each

909 site received three installations of three treatments randomly assigned to a $3 \times 3$ grid.

910 Treatments included b) closed cages to exclude insects, c) open cages providing similar

911 microclimatic conditions as closed cages but giving access to insects and d) uncaged bundles

912 of logs. Cages measured $40 \times 40 \times 60 \mathrm{~cm}$ and were made of white polyester with honeycomb-

913 shaped meshes with a side length of approx. $0.5 \mathrm{~mm}$. Open cages had four rectangular

914 openings measuring $3 \times 12 \mathrm{~cm}$ at both front sides and four rectangular openings measuring

$91510 \times 15 \mathrm{~cm}$ at the bottom representing in total $6 \%$ of the surface area of the cage as well as a

916 total of ten $12 \mathrm{~cm}$ slits at the top and long sides. All cages were placed on stainless steel mesh

917 (0.5 mm mesh width), which had the same openings as the bottom side of the cages in the

918 open cage treatment. Photographs show the site in the Bavarian Forest National Park,

919 Germany.

920 Extended Data Figure 2 | Effects of treatments on wood decomposition and insect

921 colonization. Coefficients and confidence intervals from post-hoc tests assessing all three 922 pairwise comparisons between the uncaged, closed cage and open cage treatments for a) 923 annual mass loss (same structure as the model shown in Table 1 based on 3578 logs) and b) 924 insect colonization (binomial model for insect presence and absence based on 3430 logs) of 925 wood of native tree species. 95\% confidence intervals not intersecting the zero line (dashed) 926 indicate significant differences. c) Pairwise comparison of fitted annual mass loss (in \%) 927 between each of the three treatments in the global deadwood decomposition experiment. 928 Points represent predicted values for angiosperm species at 55 sites and gymnosperm 929 species at 21 sites based on three Gaussian generalized linear mixed log-link models for 3758 930 logs with site-specific random effects and temperature, precipitation, treatment (closed cage 931 versus uncaged, open cage versus uncaged and closed cage versus open cage, respectively), 932 host division, as well as their interactions, as fixed effects.

933 In a) and b), largest differences in both response variables were observed between uncaged 934 and closed cage treatments. Annual mass loss was higher in uncaged than open cages and 
935 higher in open cages than in closed cages, although the latter was not significant. This

936 indicates that the open cage, despite its openings for insects, has a clearly reduced

937 decomposition rate compared to the uncaged treatment. Insect colonization for the open cage

938 differed significantly from both uncaged and closed cage, but was more similar to uncaged

939 than closed cage. This indicates that open cages were colonized by insects, but not as

940 frequently as the uncaged treatment. Open cages thus excluded parts of the wood-

941 decomposing insect community, which may explain the rather small difference in annual mass

942 loss between closed cage and open cages. These results suggest that the comparison of

943 uncaged versus closed caged provides a more reliable estimate of the net effect of insects on

944 wood decomposition than the comparison of closed cage versus open cage treatments, which

945 is likely underestimating the net effect of insects. In c), the difference between annual mass

946 loss in closed cage and both treatments with insect access (uncaged and open cage)

947 increased from boreal to tropical, whereas the difference between uncaged and open cage

948 hardly deviated from the 1:1 line. This indicates that the reported mass loss differences

949 between closed cage and uncaged treatments, as well as the accelerating effect of

950 temperature and precipitation (Table 1), can be attributed to insects and are not an artefact of

951 potential microclimatic effects of the cages (Supplementary Information section 1).

952 Extended Data Figure 3 | Interaction effects of temperature and precipitation on wood

953 decomposition. Predictions based on the model presented in Table 1 for a) annual mass loss

954 of deadwood of native tree species (2533 logs at 55 sites), considering all possible groups of

955 decomposers (treatment uncaged) and b) annual mass loss attributed to insects (difference in

956 mass loss between treatments uncaged and closed cage), relative to temperature and

957 precipitation. The length of the lines is limited to the gradients in precipitation covered by the 958 sites. 
960 Extended Data Figure 4 | Model evaluation against independent data. Comparison of 157

961 independent observations of annual deadwood decomposition rates measured for larger 962 diameter wood in previous deadwood surveys (red dots, Harmon et al. ${ }^{28}$ ) with the predictions 963 from our model for the same locations (blue triangles). Lines indicate the relationship between 964 decomposition rate and mean annual temperature from Harmon et al. ${ }^{28}$ (red dashed line, $965 \mathrm{k}=0.0184 \mathrm{e}^{0.0787^{\star} \text { temperature }}$ ) and for our model (blue line, $\mathrm{k}=0.0171 \mathrm{e}^{0.0812^{\star} \text { temperature }}$ ). Good 966 correspondence of both curves indicates that our models of global carbon release from 967 deadwood provide robust estimates despite being based on experimental deadwood with $\sim 3$ $968 \mathrm{~cm}$ diameter (for detailed discussion, see Supplementary Information section 1).

969 Extended Data Figure 5 | Global deadwood carbon fluxes. a) Total annual release of 970 deadwood carbon from decomposition including all decomposers and b) annual release of 971 deadwood carbon due to the net effect of insects. Light grey areas indicate values of $\pm 0.1 \mathrm{Mg}$ 972 carbon ha ${ }^{-1} \mathrm{a}^{-1}$ and white areas are non-forest systems. c) Latitudinal distribution of global 973 deadwood carbon fluxes per hectare.

974 Extended Data Figure 6 | Processing steps for the global deadwood carbon map a)

975 Aboveground forest biomass $\left(\mathrm{Mg} \mathrm{ha}^{-1}\right)$ aggregated to 5' from the GlobBiom data set. b) Total 976 live carbon $\left(\mathrm{Mg} \mathrm{ha}^{-1}\right)$ by extending a) with root biomass ${ }^{56}$ and conversion to carbon. c) 977 Proportion of gymnosperm forests derived from the GLCNMO2013 ${ }^{60}$ data set. The proportion 978 of angiosperm cover is $1-$ gymnosperm cover. White $=$ non-forested area.

979 Extended Data Figure 7 | Bioclimatic space for robust predictions. Climate conditions 980 outside of the range of prediction models for a) angiosperm and b) gymnosperm species in 981 climate space (left) and mapped (right). Left: dark-blue points are outside of the range defined by a convex hull around the experimental sites (black triangles). Right: The colors on the maps 983 indicate the absolute difference between the local climate and the climate used for prediction

984 for temperature (red color channel) and precipitation (blue color channel) with black meaning 985 no difference. White areas indicate that no gymnosperm or angiosperm forest, respectively, 
986 occurs here. Experimental sites are indicated by yellow dots. Temperatures outside of the 987 range are mainly located in north-eastern Siberia and northern Canada, whereas offsets in 988 precipitation are stronger for gymnosperms in south-eastern Asia, Indonesia, and in the 989 Amazon region. The land surface area not covered by our experimental data is $23.5 \%$ for 990 gymnosperms and $17.7 \%$ for angiosperms, representing together $13.2 \%$ of the $C$ stored in 991 deadwood. These areas were included in our upscaling by mapping them to the nearest point 992 at the convex hull in climate space. 


\section{$\mathrm{MgC} \mathrm{ha-1}$}

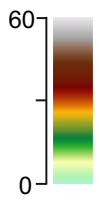

b Annual mass loss

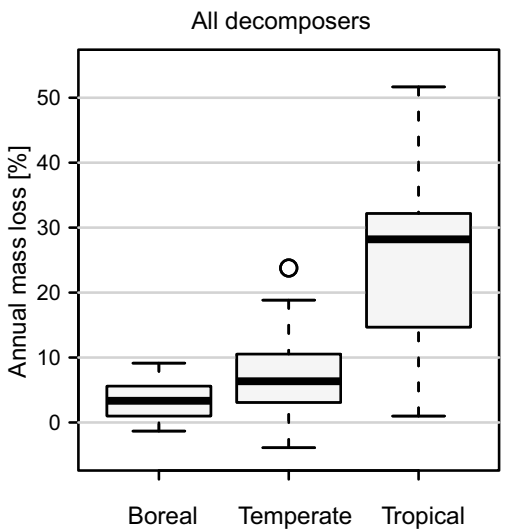

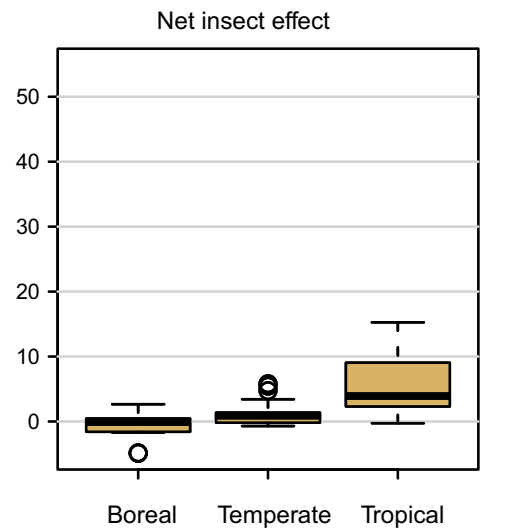




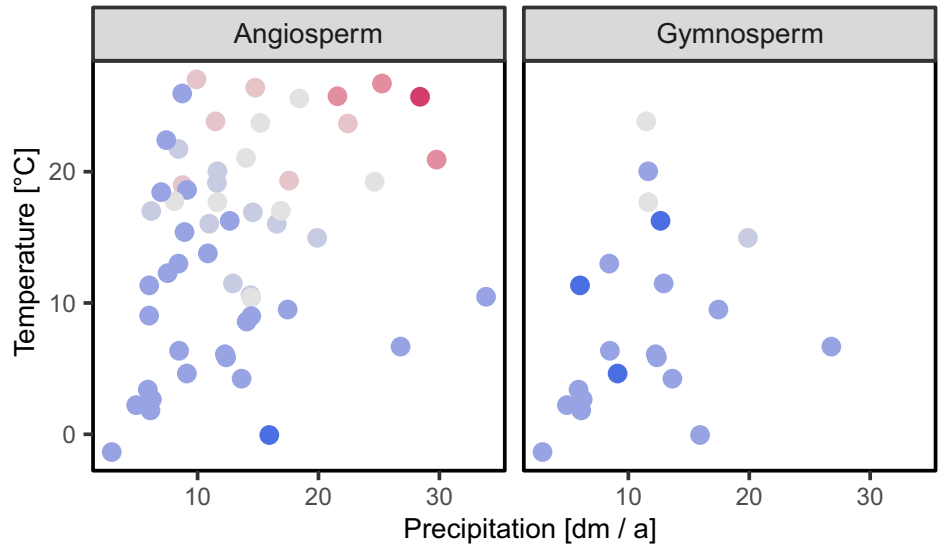

Annual mass loss

$-10 \%-0 \%$

- $0 \%-10 \%$

$10 \%-20 \%$

$20 \%-30 \%$

$30 \%-40 \%$

$40 \%-50 \%$

$50 \%-60 \%$

b Net insect effect

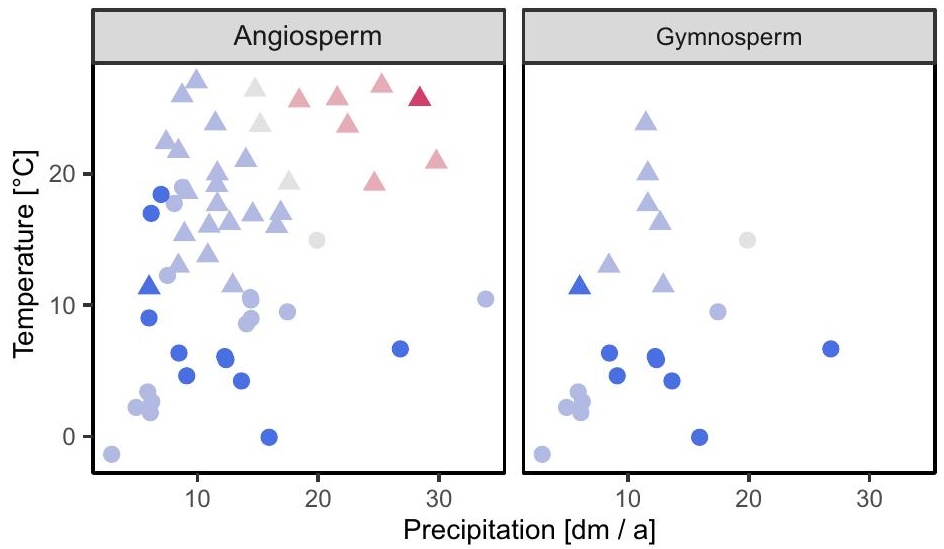

Annual mass loss

$-5 \%-0 \%$

$0 \%-5 \%$

$5 \%-10 \%$

$10 \%-15 \%$

$15 \%-20 \%$

Termites

$\Delta$ Yes

- No 


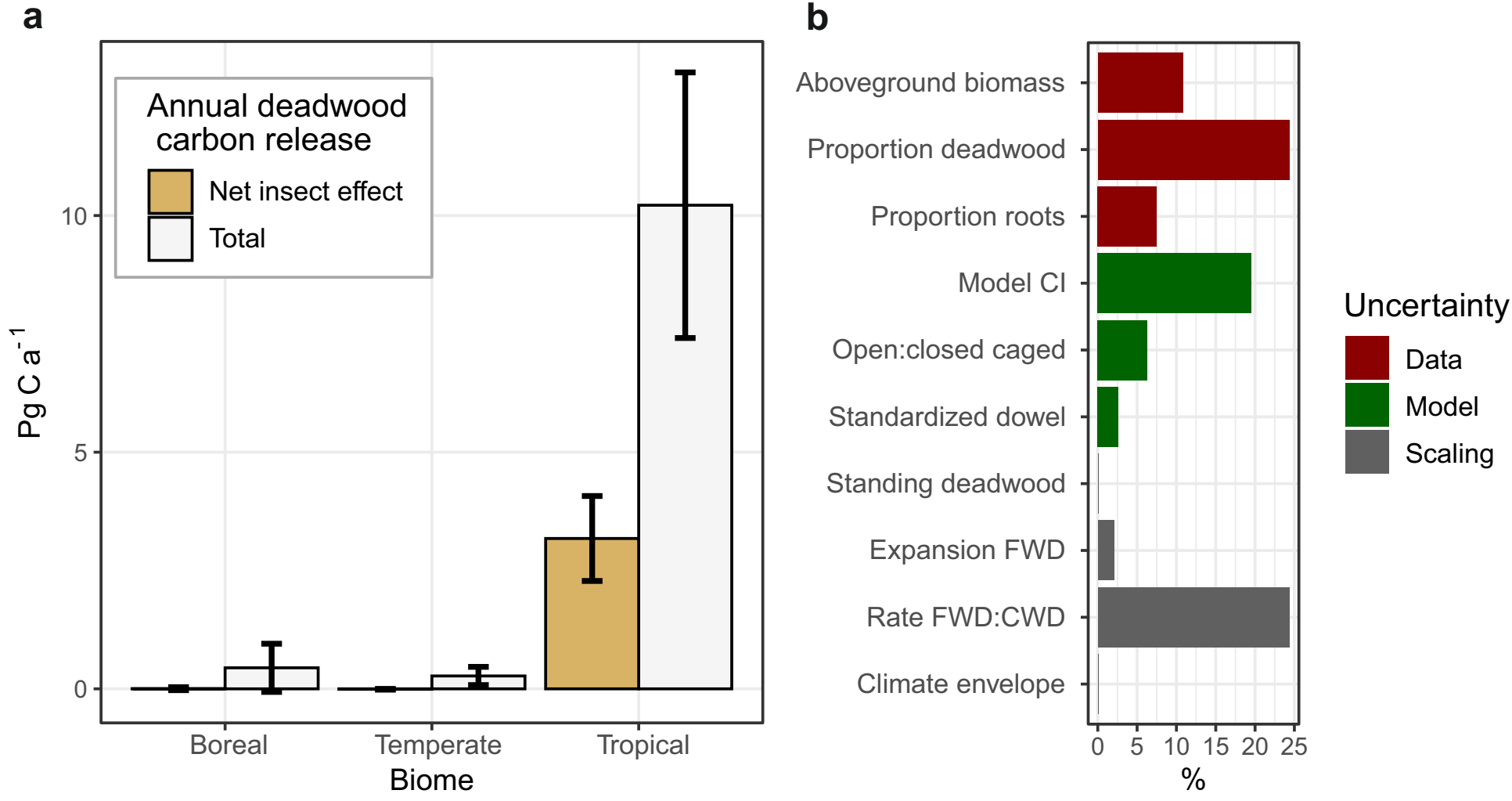


a Arrangement of installations
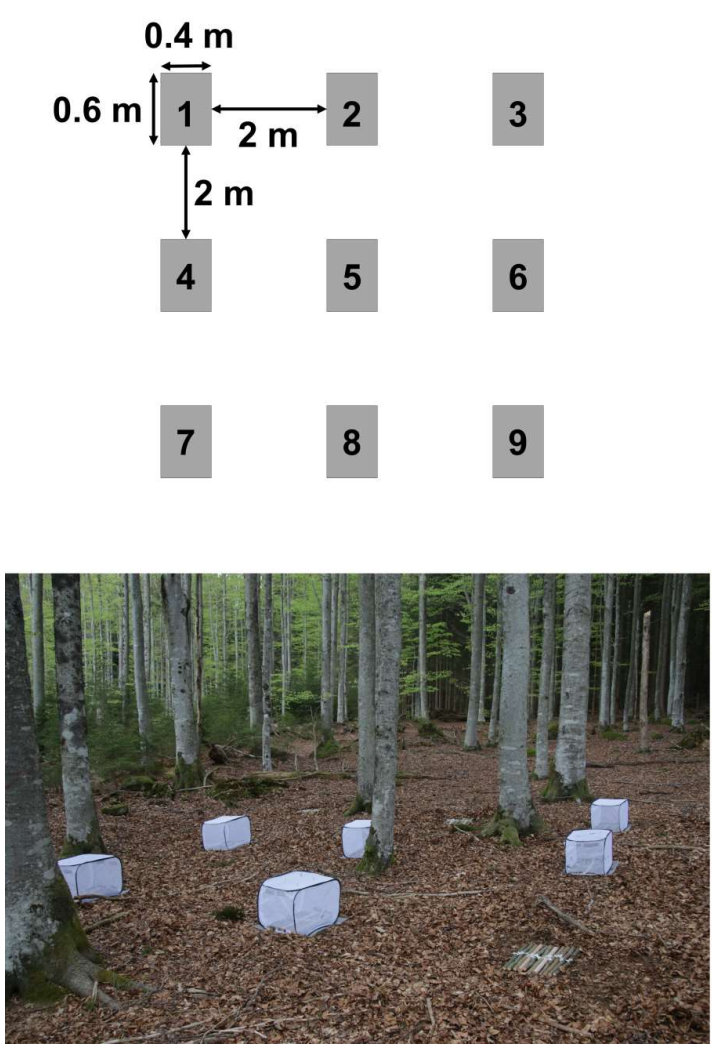

b Closed cage
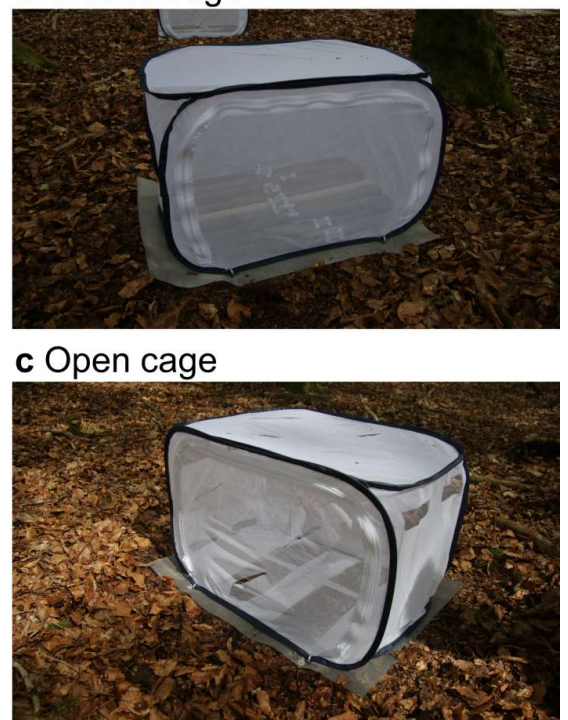

d Uncaged

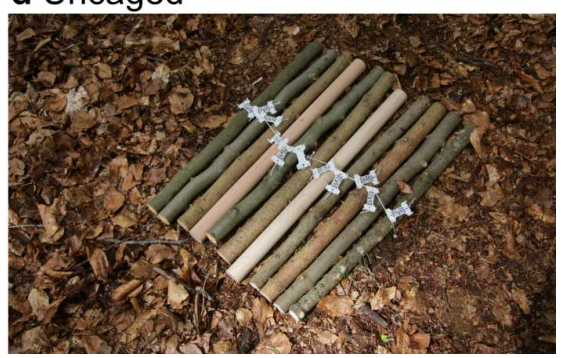



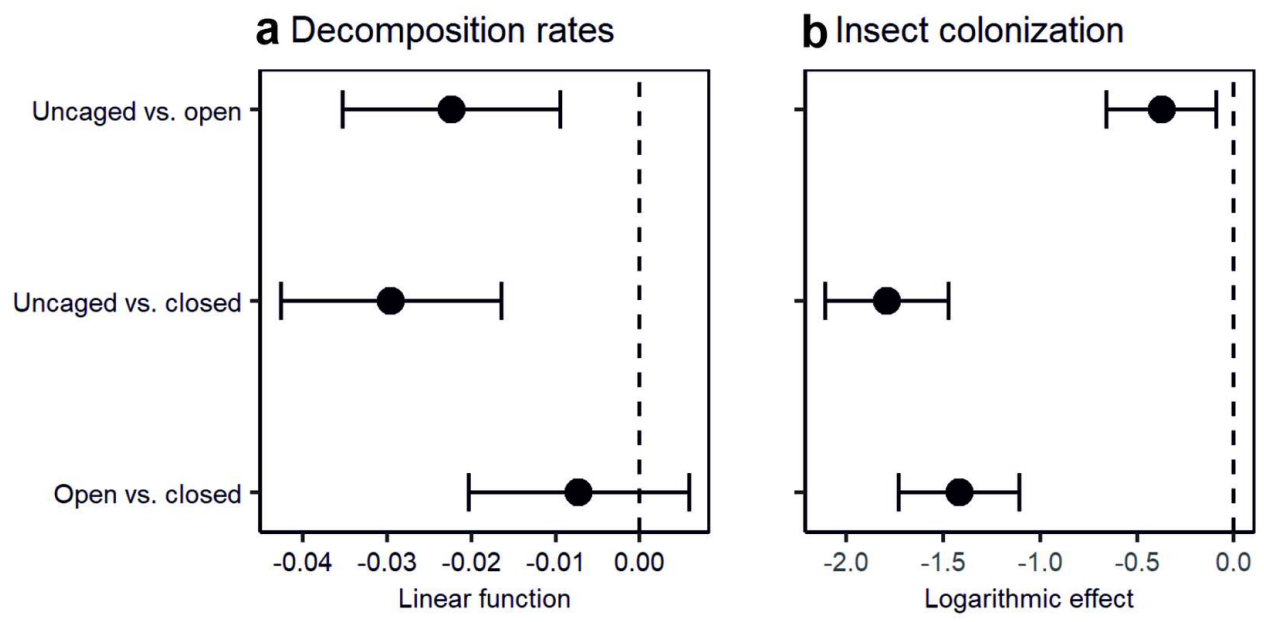

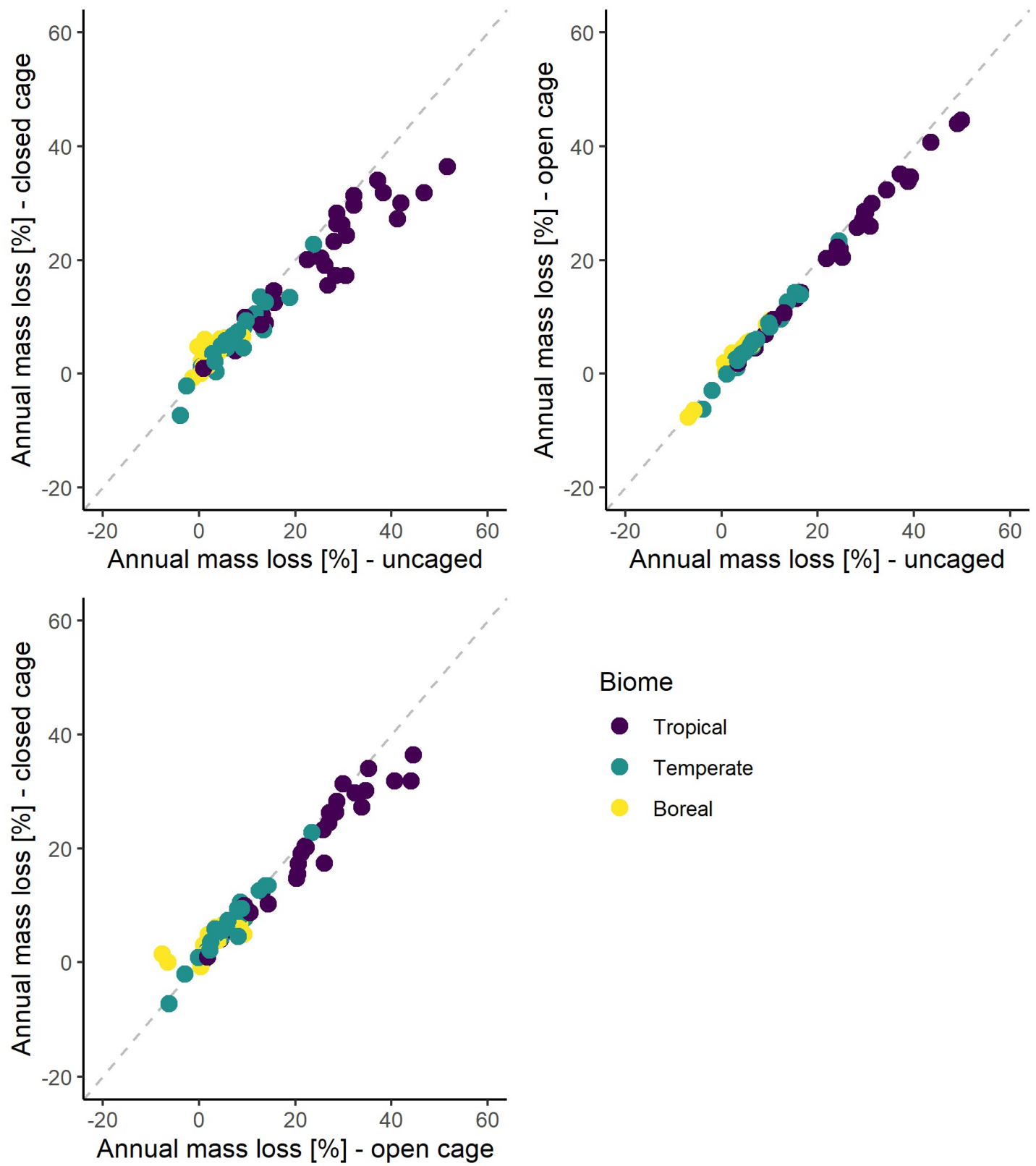

Biome

- Tropical

- Temperate

- Boreal 


\section{a All decomposers}
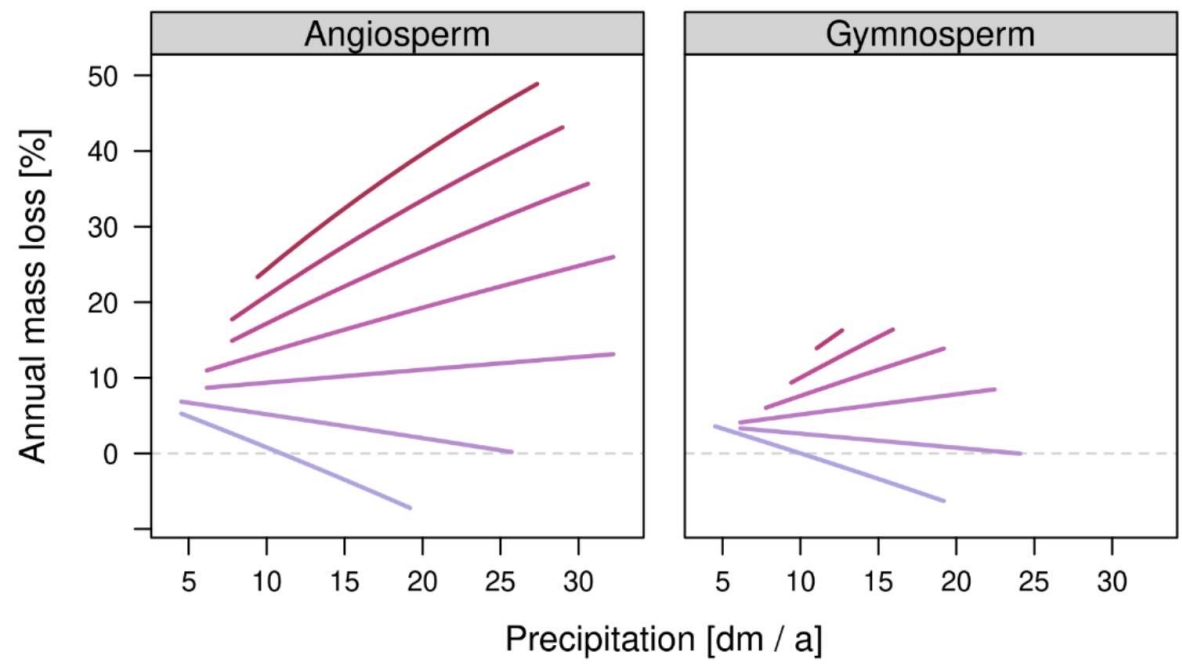

Temp. $\left[{ }^{\circ} \mathrm{C}\right]$

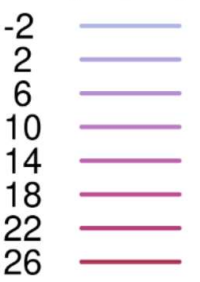

b Net insect effect
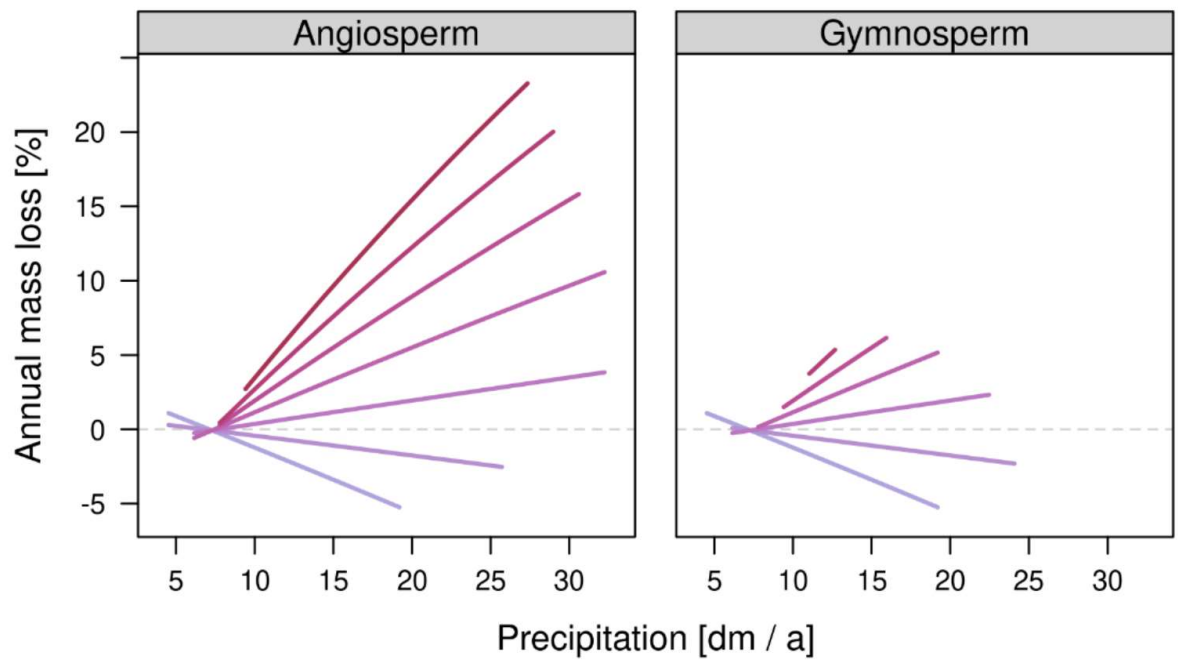

Temp. $\left[{ }^{\circ} \mathrm{C}\right]$

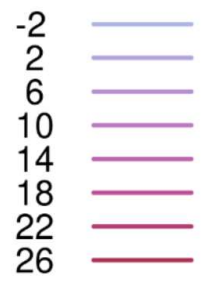

Precipitation [dm / a] 


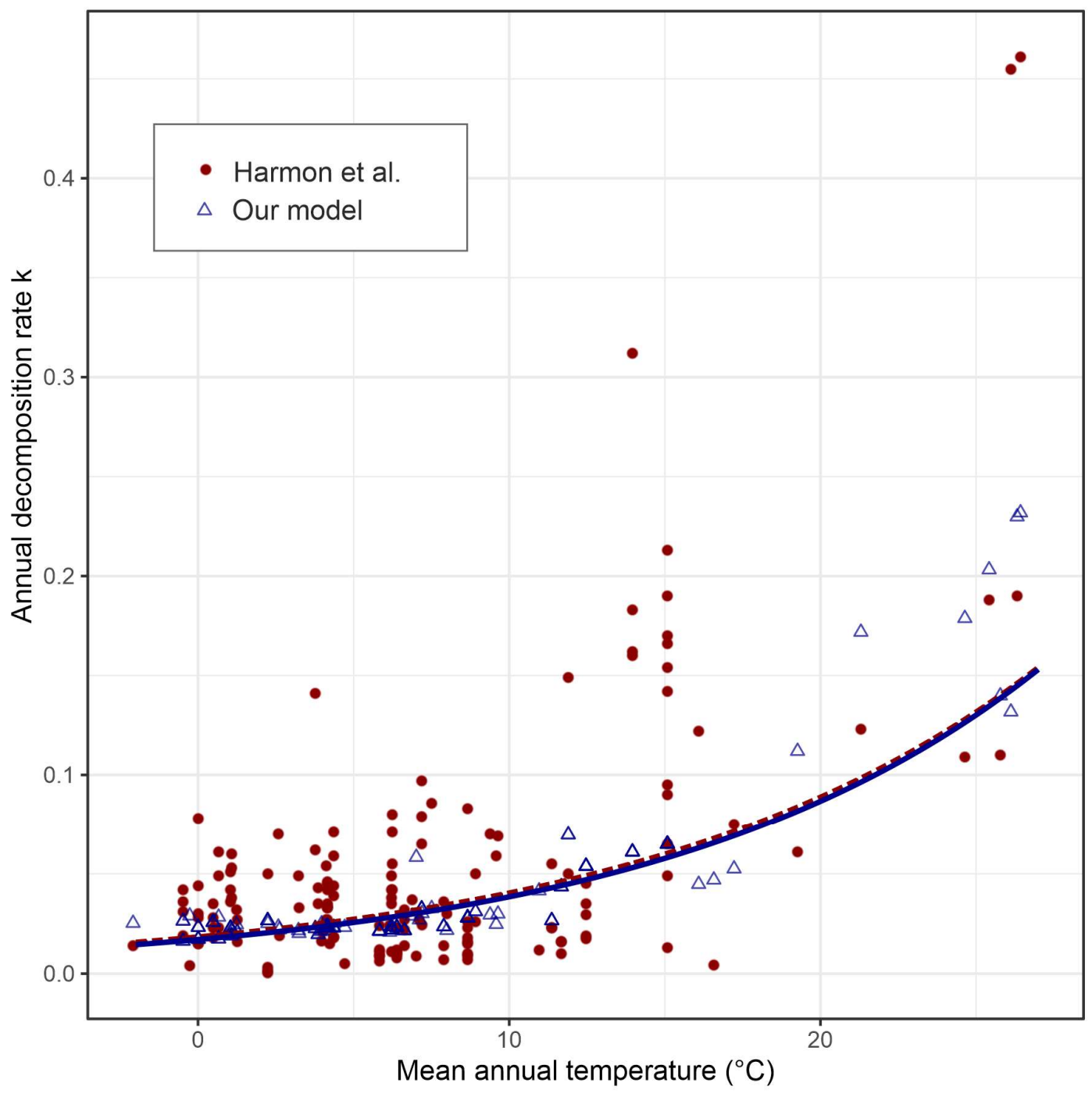


a Annual deadwood carbon release

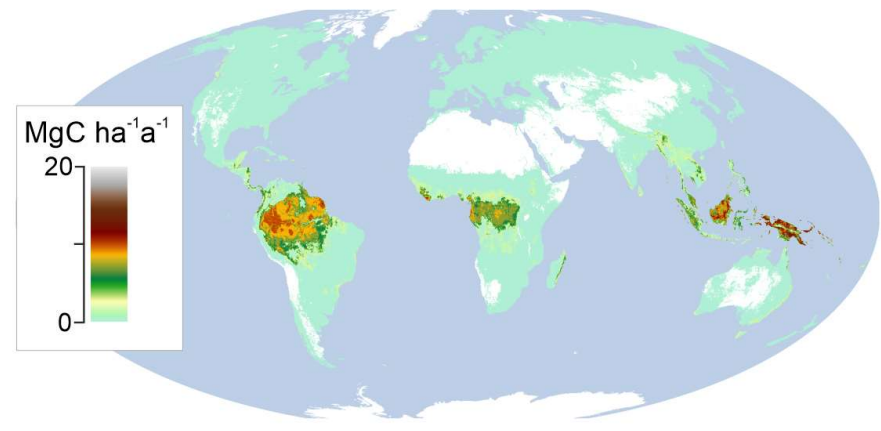

b Net insect effect

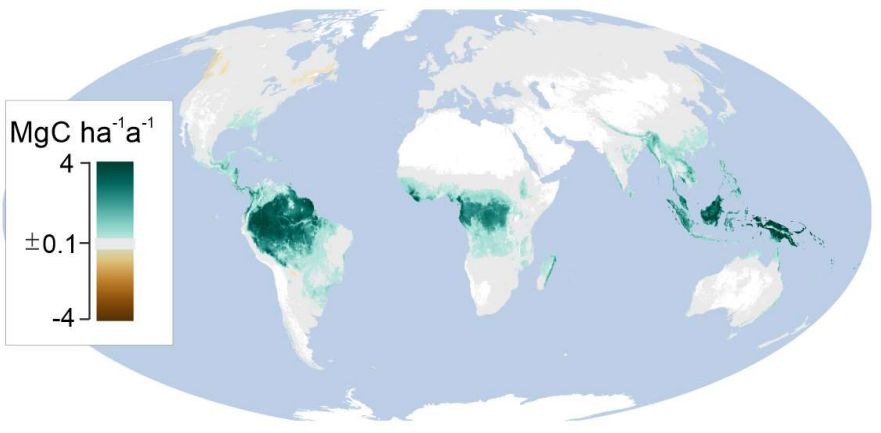

c Latitudinal distribution

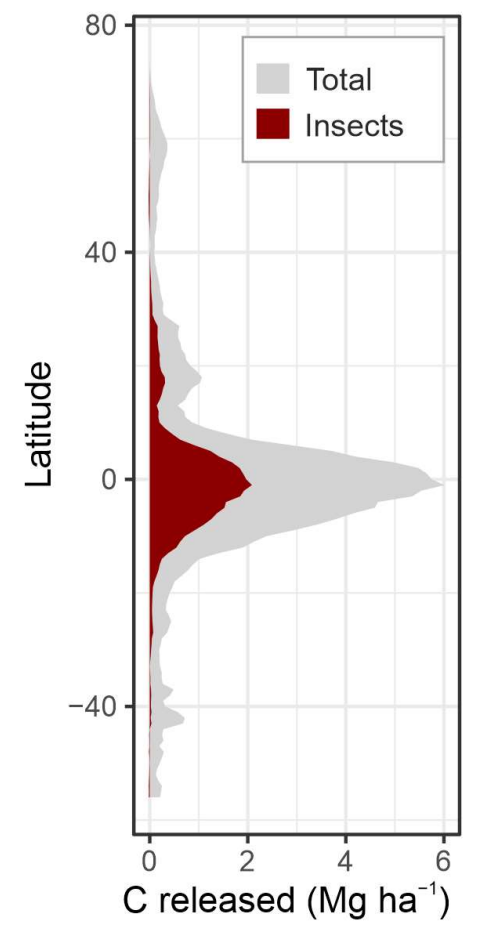



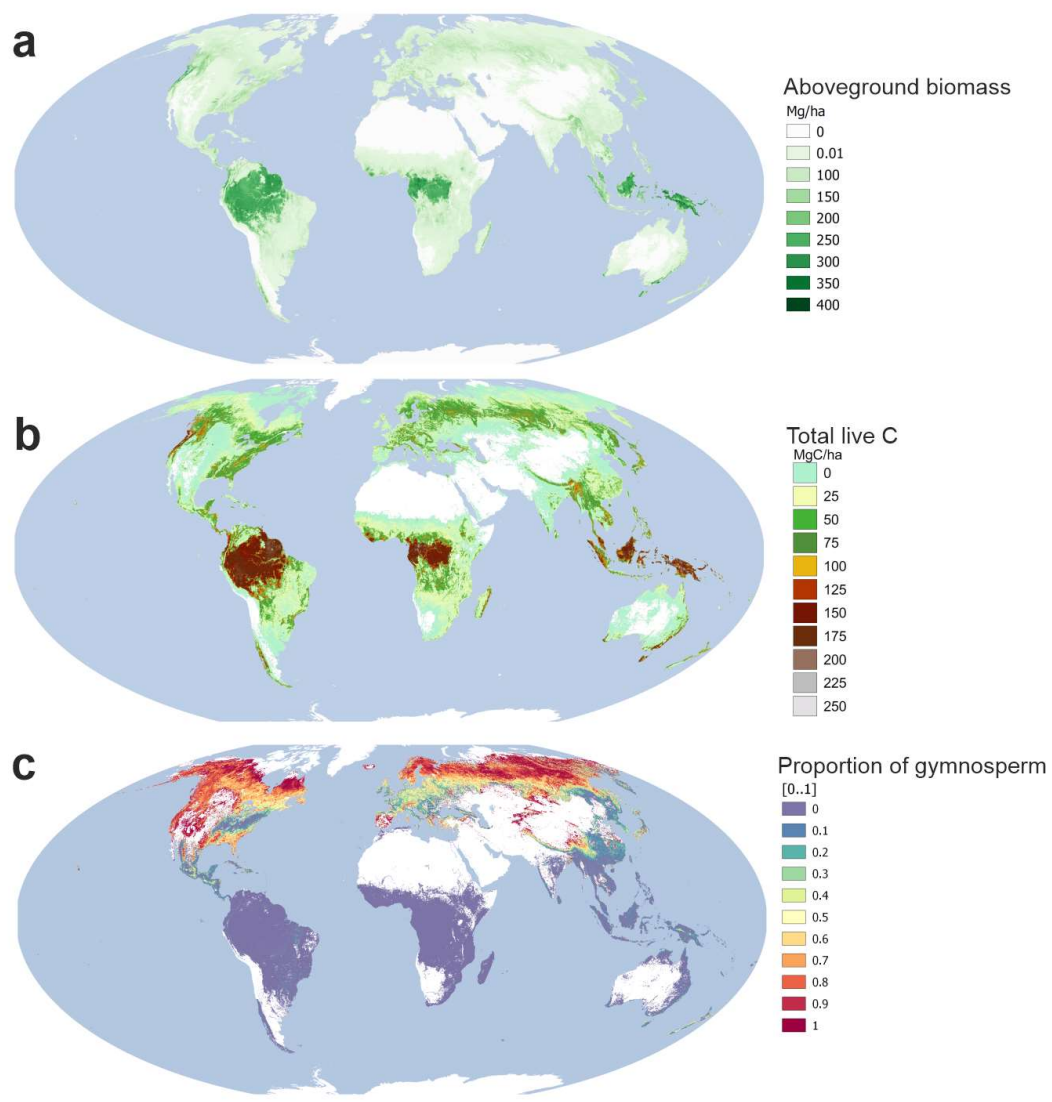
a Angiosperm

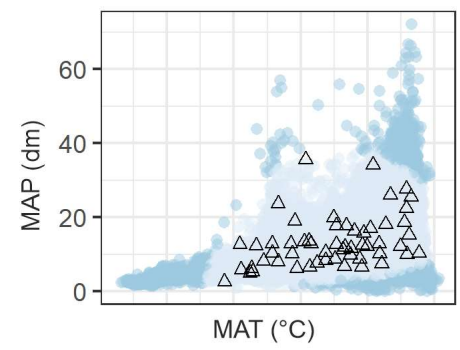

b Gymnosperm

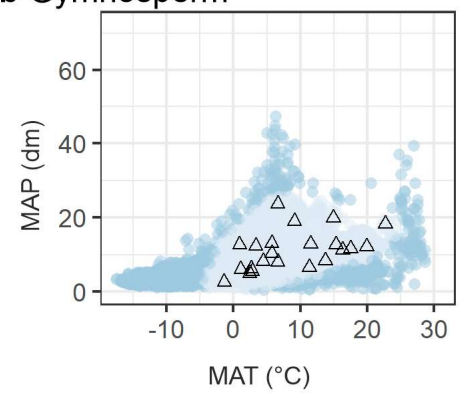

Sites

Not present

- Celsius

$\left.{ }^{10}\right]$

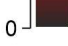

$\Delta$ precip

${ }_{1000} \mathrm{~mm}$

\section{4.}

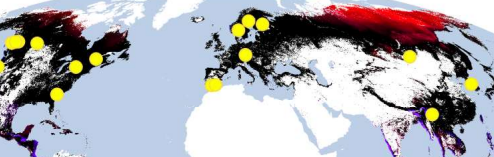

ret

(2)

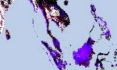

1

$\operatorname{lin}_{\pi \rightarrow}$

0 